\title{
The Voluntary Disclosure of Companies Listed on Palestine Exchange and Its Effect on Stock Price
}

\section{Bahaaeddin Ahmed Alareeni*}

University College of Applied Sciences,

Gaza Strip, Palestine

Email: bareeni@ucas.edu.ps

\section{Mohammed Salem Lulu \\ University College of Applied Sciences, \\ Gaza Strip, Palestine}

Received July, 2018; Accepted September, 2018

\begin{abstract}
This study aims to measure the quality and the quantity of voluntary disclosure (VD) using a sample of 45 companies listed on Palestine Stock Exchange for the year 2014. It also examines the impact of VD on stock prices. To measure VD, the inductive approach and content analysis of annual reports were employed, using a voluntary disclosure checklist made of 84 statements. To examine its impact on stock prices, a regression analysis was adopted. The results show that there is a significant difference in voluntary disclosure rate from one industry to another, and even between companies within the same industry. While the overall mean voluntary disclosure rate is $36 \%$, the banking sector was the most committed sector with a rate of $70 \%$, while the real estate sector was the least committed one with a rate of $36 \%$. Results suggest that Palestinian companies do not have a significant VD rate, and they should work on strengthening and improving their disclosure. The regression analysis shows that VD level does not significantly affect the stock price. Finally, the study recommends the Palestinian companies to increase their VD level given its usefulness to the companies and to several parties including users of accounting information, accounting policymakers.
\end{abstract}

Keywords: Voluntary Disclosures; Palestine Exchange; Stock Price.

Type: Research paper

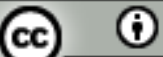

This work is licensed under a Creative Commons Attribution 4.0 International License.

DOI: 10.51325/ijbeg.v1i3.42

$$
\text { الإفصاح الاختياري للشركات المدرجة في بورصة فلسطين وأثره على سعر السهم السوقي }
$$

ملخص

$$
\begin{aligned}
& \text { هدفت هذه الدراسة إلى قياس مستوى الإفصساح الاختياري في التقارير السنوية للشركات المدرجة في بورصـة } \\
& \text { فلسطين للعام } 2014 \text { وذلك لعدد } 45 \text { شركة، وأيضـاً بيان أثر مستوى الإفصساح الاختياري على أسعار أسهم هذه إنه } \\
& \text { الثركات. استخدمت الدراسة المنهج الاستقرائي وأسلوب تحليل المحتوى في تحليل حجم الإفصاح الاختيار ونوعيته، } \\
& \text { وذلك من خلال أداة الدراسة المستخدمة وهي قائمة أسئلة (Checklist). واعتمدت الدراسـة أيضـاً تحليل الانحدار } \\
& \text { لبيان أثر مستوى الإفصساح الاختياري لدى الثركات على الأسعار السوقية لأسههها. وقد بينت النتائج أن هناك } \\
& \text { تباين في حجم ونوعية الإفصاح الاختياري بين الشركات، حيث تفاوت مستوى الإفصاح الاختياري من قطاع إلى } \\
& \text { آخر ومن شركة إلى أخرى، فكان قطاع البنوك هو أكثر القطاعات التزاماً بالإفصاح الاختياري بنسبة 70\%، وكان } \\
& \text { أقل القطاعات التزاماً قطاع العقارات بنسبة 36\%، بينما بلغت النسبة الإجمالية للإفصساح الاختياري في إجمالي }
\end{aligned}
$$


القطاعات (للسوق ككل) 54\%، إذ تعتبر هذه النسبة ضعيفة نسبياً، وتدلل بشكل عام على أن الثركات لا تلتزم

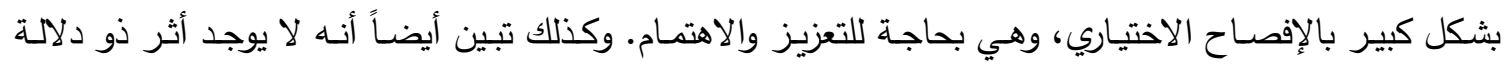

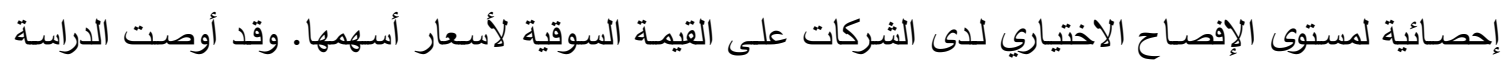
بضرورة زيادة مستوى الإفصاح الاختياري لدى الشركات، وذلك للفوائد الكبيرة التي يمكن لأطراف عدة الاستفادة منها وخاصةً الثركات نفسها.

الكلمات الدالة: الإفصاح الاختياري، بورصة فلسطين، سعر السهم.

(المقدمة

إن المعلومات المالية المنشورة في القوائم المالية للشركات المدرجة في الأسواق المالية المحلية والعالمية تؤثر بثكل كبير على وظيفة الأسواق المالية (Ho and Wong, 2001). فالمستثمرون بحاجة بانتظام إلى فئى

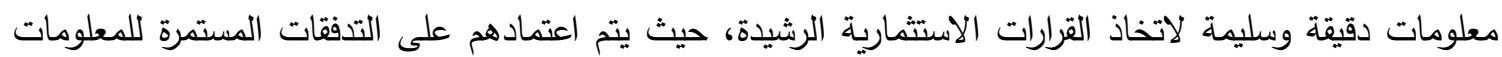

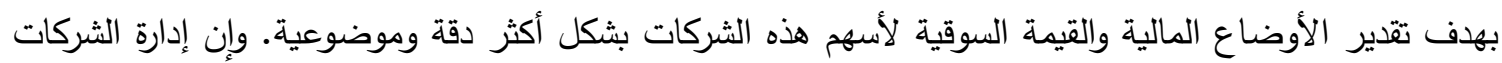

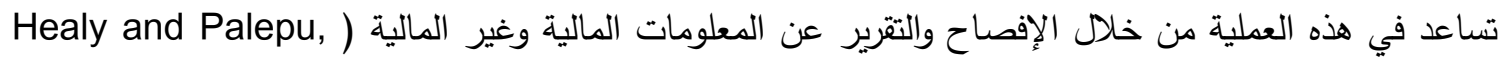
.(2001

وبناءً على ذلك فإن الانهيارات والفضائح المالية التي تعرضت لها الشركات الكبرى في العالم مثل إنرون وورلدكوم وغيرها تعتبر من العوامل التي زادت الحاجة للإفصاح كعنصر من عناصر الرقابة على أنشطة المنشآت وأعمالها. وإن الأزمة المالية التي حدثت في آسيا عام 1998 أوضحت مدان مدى أهمية الإفصاح عن المعلومات المالية، حيث تبين أن من أهم العوامل التي ساهدت في هذه الأزمة هو عدم الثفافية في المعلومات المنشورة عن الثركات

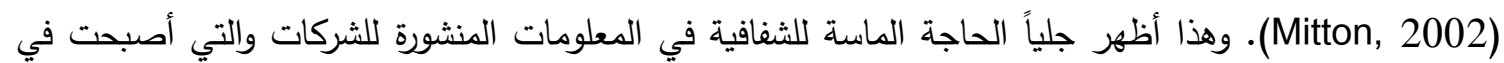

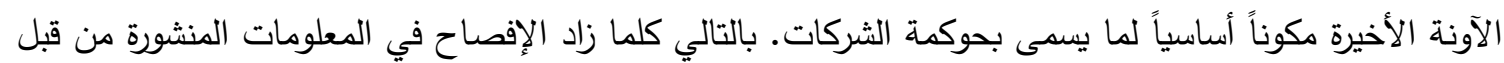
الثركات كلما زادت مستوى الثقة في الأسواق المالية (Bushman and Smith, 2001). ولهذا اهتمت الجهات المنظمة لمهنة المحاسبة بالعرض والإفصاح من خلال إصدار لجنة معايير المحاسبة الدولية لعدة معايير حددت فيها قواعد خاصة تبين كيفية ومتطلبات العرض والإفصاح، منها المعيار الدولي رقم (1) عرض البيانات المالية، والمعيار الدولي رقم (24) إفصاحات الأطراف ذات العلاقة، والمعيار الدولي لإعداد التقارير المالية رقم (7). وكذلك أصدرت الهيئات المنظمة لعمل الأسواق المالية عدد من المتطلبات والتي عززت من الإفصاح وجودة

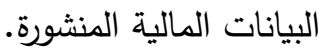
والإفصاح بشكل عام، هو إعلام المجتمع المالي بالتقارير المالية للشركات سواء كان ذلك في صلب هذه

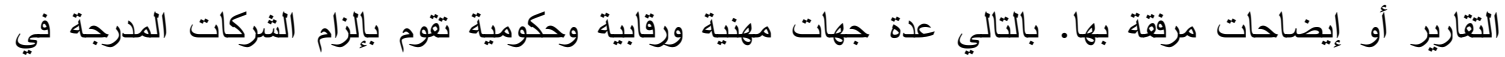

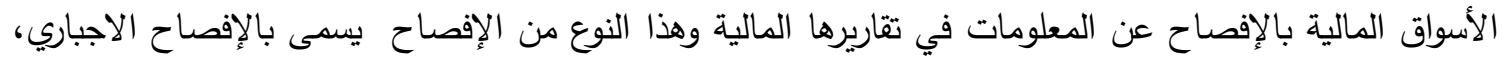

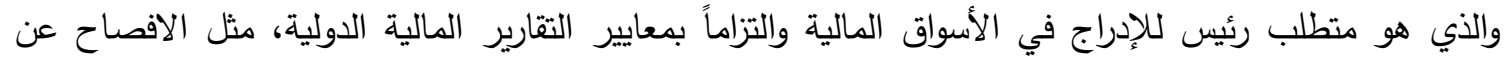
الطرق المحاسبية المستخدمة والأحداث اللاحقة لتاريخ القوائم وتحليلات الإدارة للأحداث الماضية وتتبؤاتها والقوائم المالية الإضافية التي تتعلق بنشاط الشركة، وبالتالي قد يصل مستوى التطبيق والالتزام بها من قبل الشركات إلى مستوى كبير جداً. أما النوع الآخر من الافصاح فهو الإفصاح الاختياري، هو إفصاح الثركات عن معلومات ليست ملزمة بالإفصاح عنها من أي جهة (Yuen et al, 2009). وهو يتم طوعاً وبمبادرة من إدارة الشركات وهذا الإحيات 


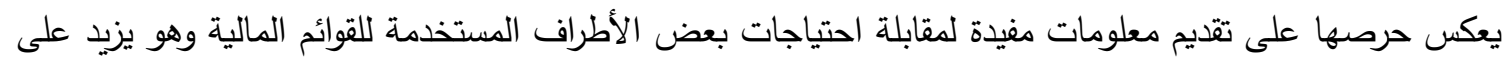
متطلبات الإفصاح الإجباري (Meek et al, 1995). ومثال عليه الإفصاح عن المؤهلات العلمية والأكاديمية للهلس الإدارة ومدى اهتمام مجلس الإدارة في منافسة الشركات الأخرى وماهية خبرات المديرين والموارد البشرية الإسية لاى الشركات وغيرها من الافصاحات، والتي قد تتفاوت من شركة إلى أخرى في الحجم وفي النوعية للمعلومات الإدات

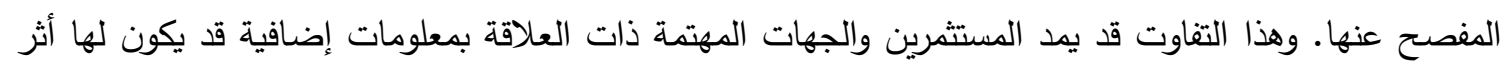
على قراراتهم الحالية وتتبؤاتهم المستقبلية، ومن ثم أسعار الأسهم لهذه الشركات. وفي بيئة الأعمال الفلسطينية، الثركات المدرجة في بورصة فلتهنة فلسطين للأوراق المالية مثلها مثل قرينتها في العالم مطالبة بواسطة أطراف عدة بأن تقوم بالإفصاحات الاجبارية. ولأن في الآونة الأخيرة قد حظي الإفصاح

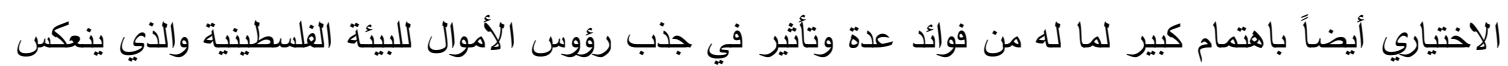

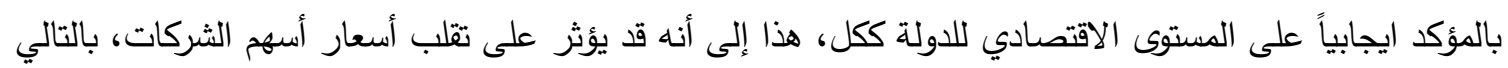

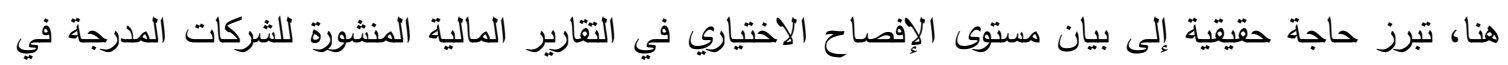

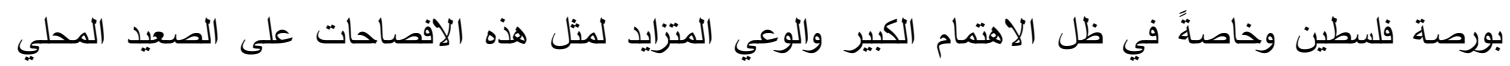
والعالمي، والذي قد يكون له الأثر الكبير على قرارات أطراف عدة منها منظمي البورصة الفلسطينية وهيئة الأوراق

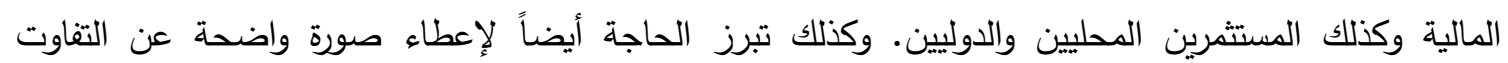
والاختلاف في نوعية وحجم الإفصاح الاختياري بين الشركات نفسها، ويزداد الأمر أهمية ببيان هل لهذا الافصاح

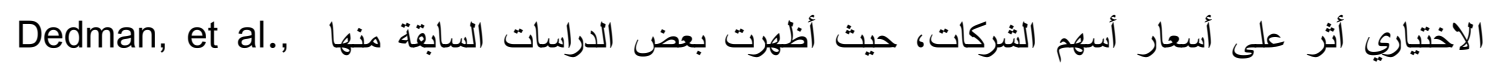

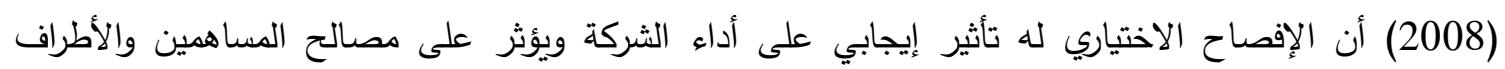
المعنية الأخرى ذات العلاقة. حيث قد تستخدم الثركات المزيد من الإفصاح الاختياري لنقل التطورات الحادثة لديها

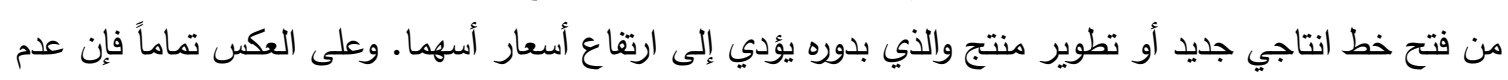

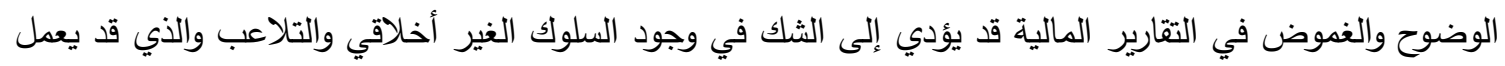
على تقليل قيمة الشركة وانخفاض أسعار أسهها. بالتالي تهدف هذه الدراسة إلى قياس مستوى الإفصاح الاختياري لدى الشركات المدرجة في بورصة فلسطين

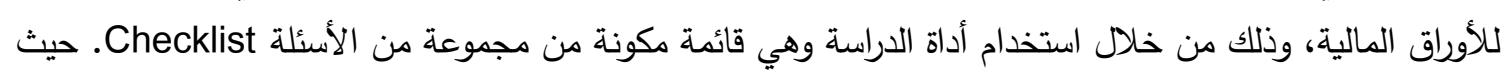

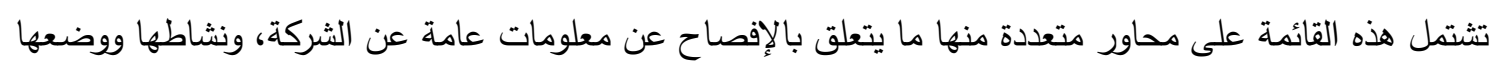

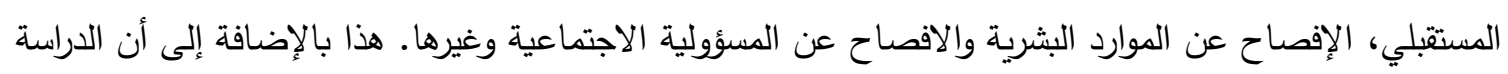

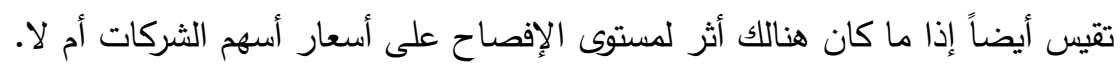

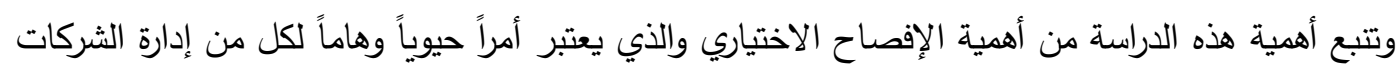

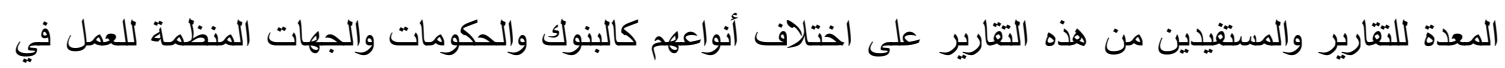
البورصة والمستثمرين على الصعيد المحلي والدولي. حيث تركز الدراسة على تطوير واستخدام قائمة أسئلة

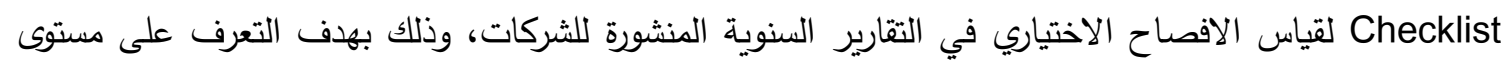
الإفصاح الاختياري لديها وطبيعة المعلومات المفصح عنها. حيث أنه حسب علم الباحثين أن معظم الدراسات

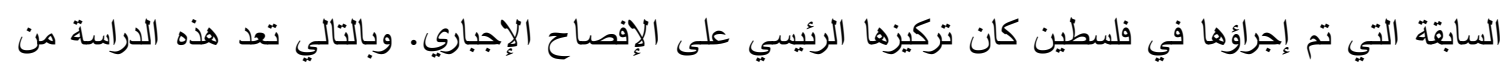

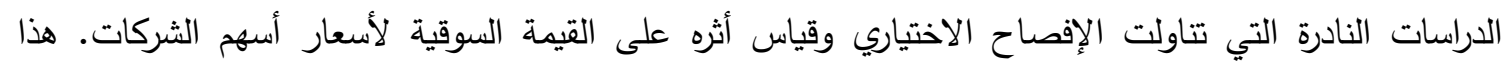

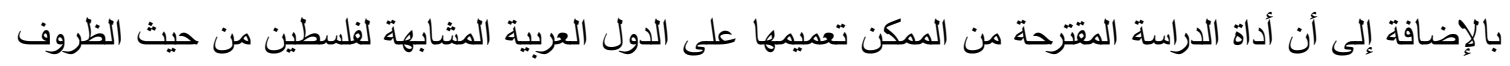


الاراسات السابقة

العديد من الدراسات السابقة تطرقت إلى موضوع الإفصاح الاختياري من عدة جوانب: حيث أن بعض العض

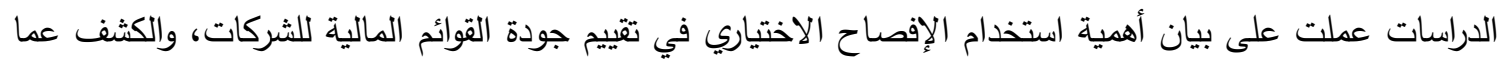
إذا كان هنالك تحسن ملحوظ وواضح في مستوى التطبيق للإفصاح الاختياري لاى هذه الثركات في ظل الوعي

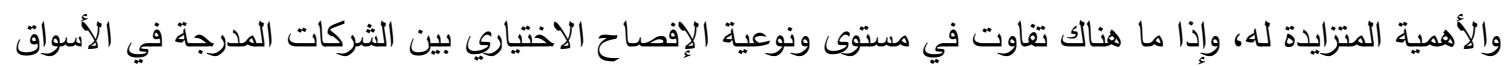
المالية. على سبيل المثال، دراسة (Binh, 2012) بحثت في تحليل الفجوة بين مطالبات المحليين الماليين ومدراء الثركات في الإفصاح عن المعلومات المناسبة، ومدى قدرة المعلومات المتاحة في التقارير السنوية للشركات الغير

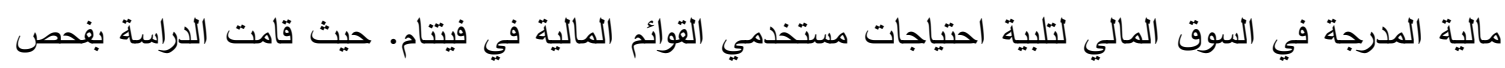
التقارير السنوية لـ 199 شركة مدرجة في السوق المالي في فيتتام لعام 2009، وبينت أن هناك اجماع كبير بين

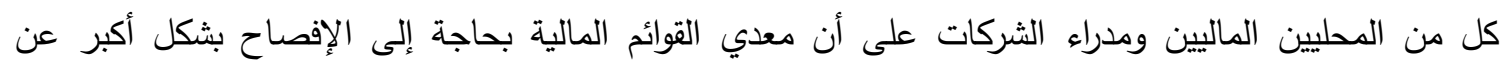

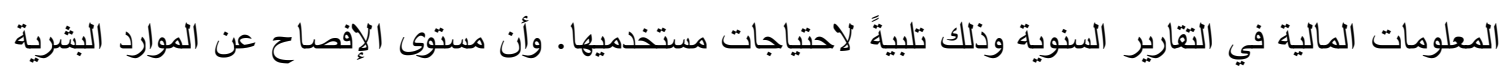
كان منخفض جداً في التقارير السنوية المنشورة للشركات. أما دراسة (Oluwagbemiga, 2014) هدفت فئت إلى اختبار مدى تطبيق الافصاحات الاختيارية في زيادة جودة القوائم المالية للشركة المدرجة في السوق المالي في نيجيريا. حيث تكون مجتمع الدراسة من جميع الثركات المدرجة في السوق المالي في نيجيريا والبالغ عددها 258 النيات

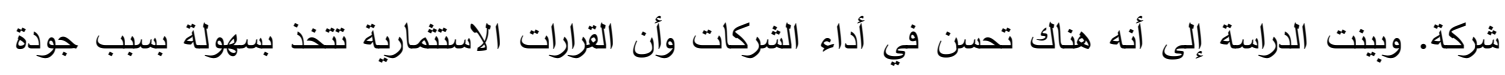

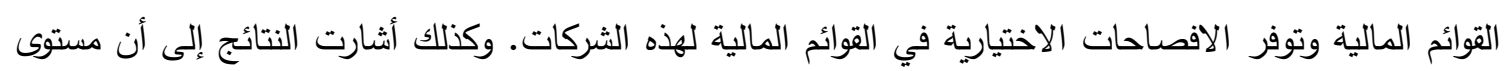
الافصاحات الاختيارية كان عالياً وهذا ما يفر سهولة اتخاذ القرارات الاستثمارية من قبل المستثرين. والبعض الآخر من الدراسات السابقة تطرق إلى دراسة أثر التغير في مستوى الإفصاح الاختياري على قيمة

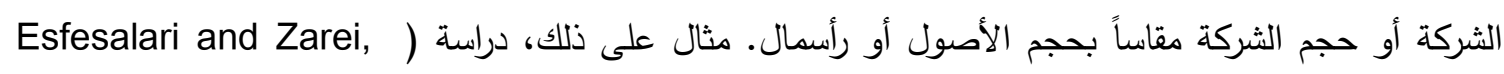

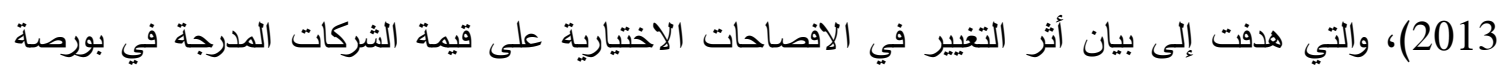

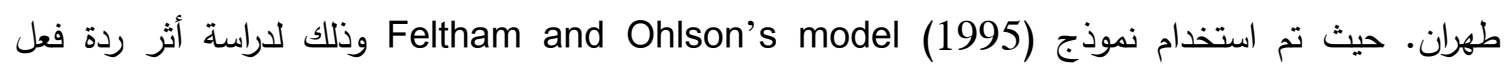
المستثمرين على صافي الأصول العاملة والايرادات التشغيلية الغير عادية للشركات التي قامت بتغيير افصاحاتها الاختيارية، حيث تم تقسيم الشركات إلى مجموعتين الأولى الشركات التي قامت بزيادة افصاحاتها الاختيارية والمجموعة الأخرى الثركات التي قامت بتخفيض حجم افصاحاتها الاختيارية، حيث بينت نتائج الدراسة أن مدراء

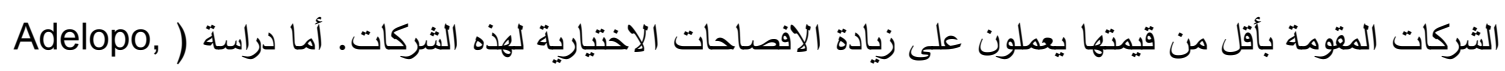

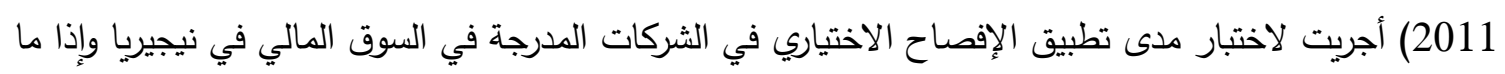

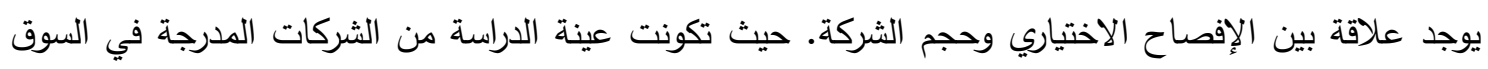

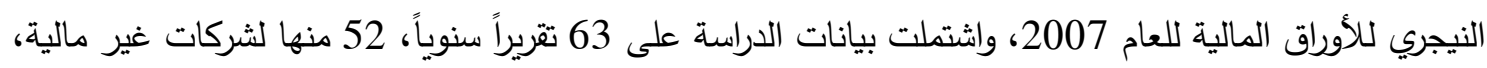
و 11 لشركات تأمين. وقد استخدمت الدراسة تحليل الانحدار المتعدد لتحليل بيانات الدراسة. وقد بينت نتائج الدراسة أنه يوجد علاقة طردية مهمة بين مستوى الإفصاح الاختياري وحجم الثركة الذي تم قياسه باللوغاريتم الطبيعي

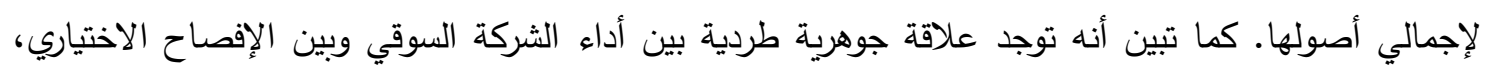

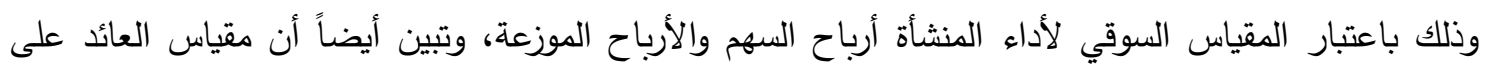

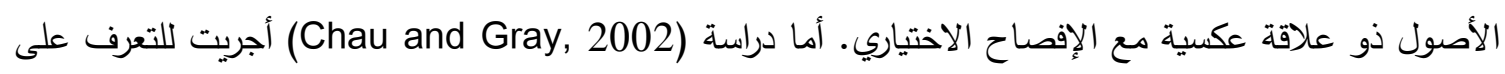


العلاقة بين هيكل الملكية والافصاح الاختياري لعدد من الثركات في هونج كونج وسنغافورا. وتكونت عينة الدراسة

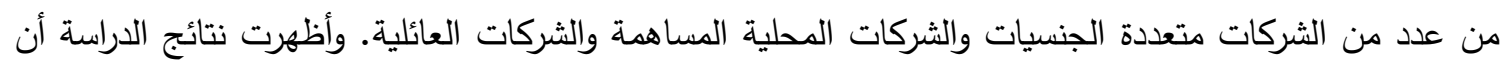
هناك علاقة طردية بين الملكية العامة ومستوى الإفصاح الاختياري، حيث تبين أن مستوى الإفصاح الاختياري

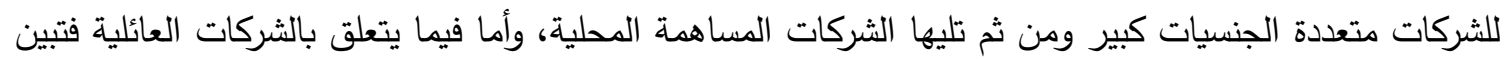
أن مستوى الإفصاح لديها قليل وهي تفصح فقط عن المعلومات الاجبارية التي تتطلبها القوانين والأنظمة. وكذلك دراسة (Hail, 2002) هدفت إلى اختبار أثر الافصاحات الاختيارية للشركات على التكلفة المتوقعة لرأس مال

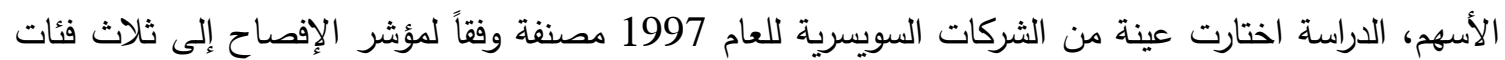

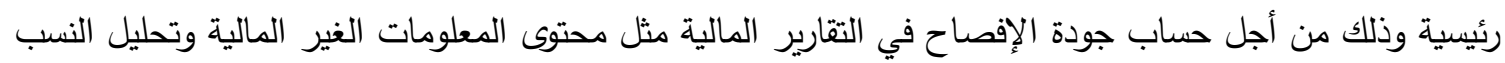

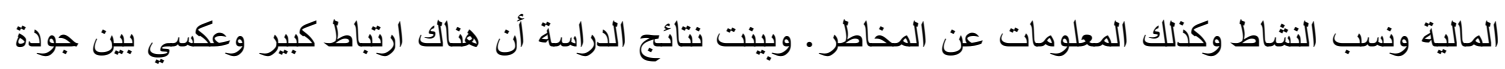
الافصاحات في التقارير المالية المنشورة والتكلفة المتوقعة لرأس مال الأسهر. وهذا بالإضافة إلى أن جزءً آخر من الدراسات تطرق إلى بيان العوامل التي تؤدي إلى زيادة الإفصاح الاختياري لدى الشركات. منها دراسة (Robb et al., 2001)، حيث هدفت هذه الدراسة إلى بيان العوامل التي لتي

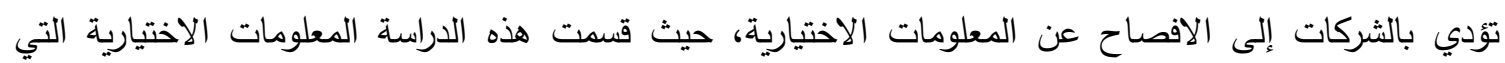

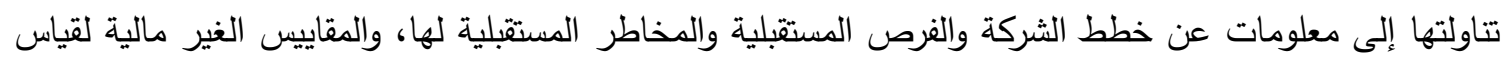

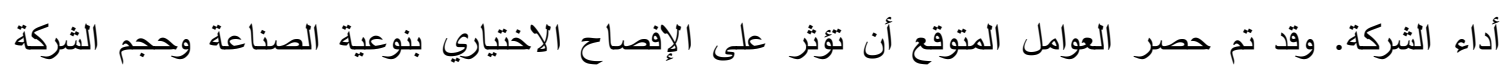
والانتشار الجغرافي للشركة والبلد الأصلي للشركة. وتكونت عينة الدراسة من 192 شركة أمريكية واسترالية وكندية

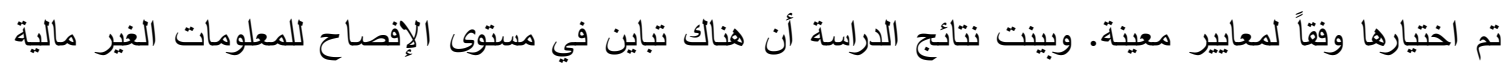

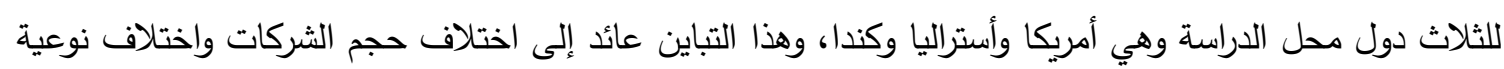

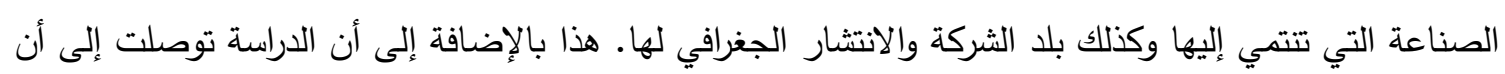
الثركات متعددة الجنسيات والتي لها أكثر من فرع في أكثر من بلد تفصح بشكل أكبر عن الثركات المحلية وأن

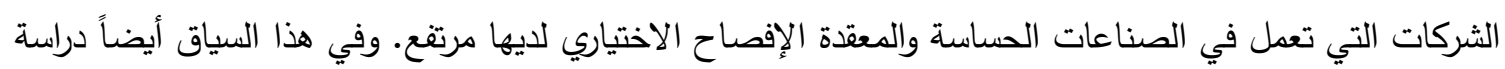
(Gray et al, 1995)

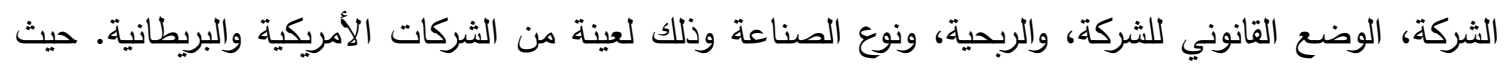

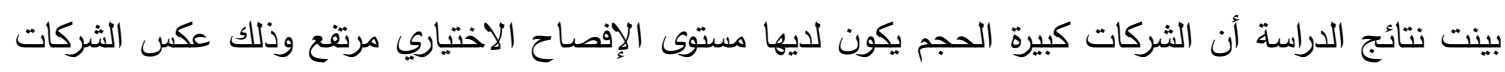

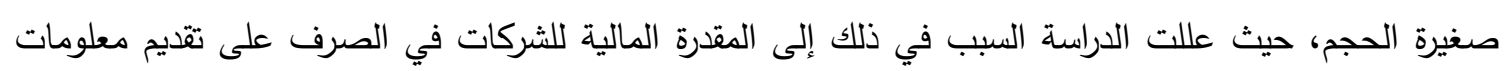

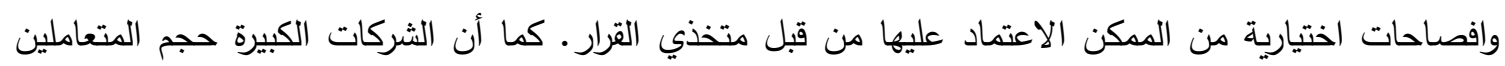
وحجم المساهمين بها كبير وهم بحاجة إلى حجم كبير من المعلومات التي لا تتطلبها القوانين والأنظمة السائدة في البلدان. وعلى صعيد نوع الصناعة، بينت الدراسة أن شركات النفط والتعدين والبتروكيمياويات أن مستوى الإفصاح لتهاح

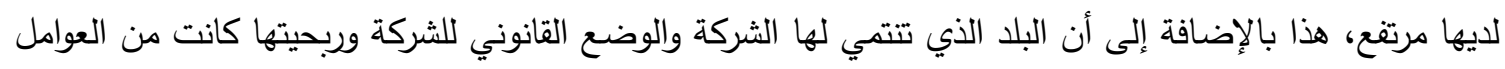

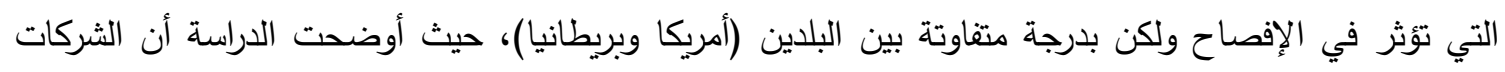
الأمريكية مستوى الإفصاح لديها أكبر من الشركات البريطانية.

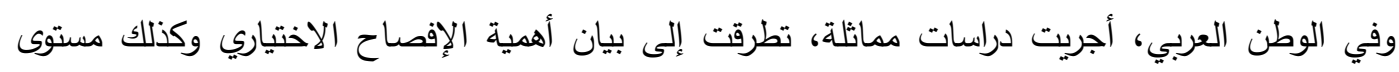

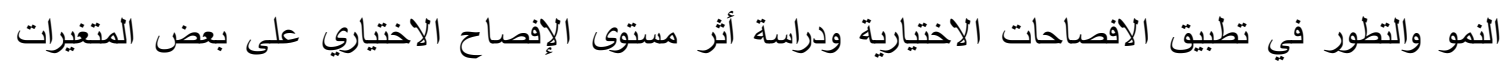
الأخرى. مثال على ذلك دراسة (الخيال، 2009) والتي سعت إلى استطلاع وجهات نظر الأكاديميين ومراجعي الإسي الحسابات وشركات الوساطة المالية حول أهمية الإفصاح الاختياري، وكذلك هدفت إلى معرفة أهم المعلومات التي التي 
يرغب المشاركون في الدراسة أن تتضمنها التقارير السنوية المنشورة للشركات السعودية بجانب محتوياتها المالية. وقد وتوصلت الدراسة إلى أن الإفصاح المصاحب للقوائم المالية للشركات المساهمة السعودية غير كاف لاتخاذ قرارات الاستثمار في الأسهم. أما دراسة (أبو شلوع، 2013) فقد عملت على تحليل توجهات الإفصاح الاختياري في الثركات المساهمة المدرج في البورصة المصرية، وذلك عن طريق تحديد مستخدمي المعلومات المنشورة التي يوجه إليها الإفصاح الاختياري الوارد بالتقارير السنوية للثركات المدرجة بالبورصة المصرية، كما عملت الدراسة على تحليل محتوى الإفصاح الاختياري في تلك التقارير • حيث تم استخدام أسلوب تحليل محتوى التقارير المالية السنوية لعينة مكونة من عشرين شركة مصرية مدرجة في البورصة المصرية لعام 2008، وهذا من الجن أجل تحديد

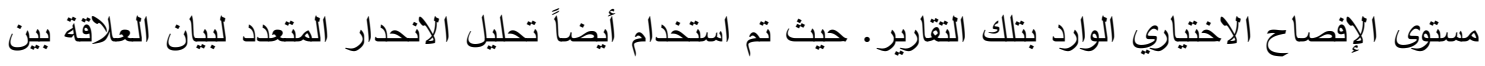

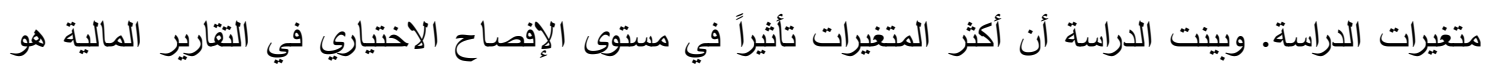
مستوى تعقد طبيعة أعمال الثركة، ومدى اهتمام الثركة بإدارة رأس المال الفكري. أما فيما يتعلق بدراسة الإستا (الخيال،

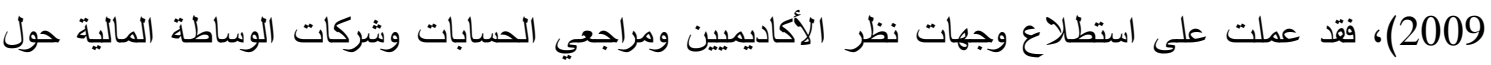

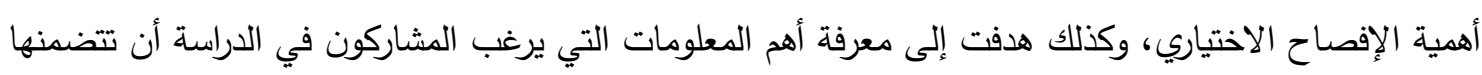

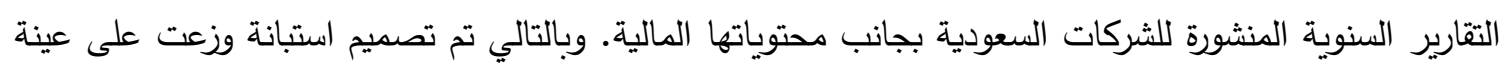

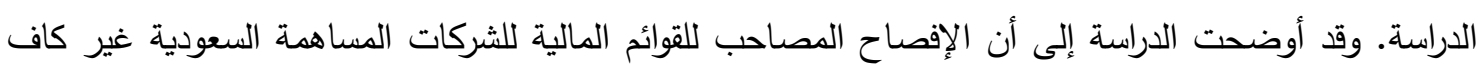

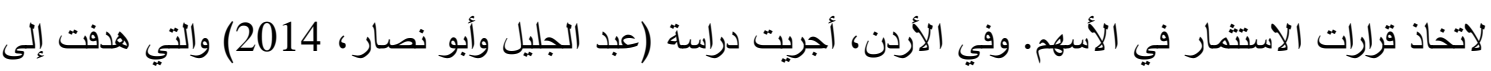

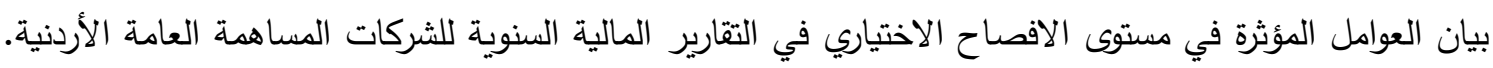

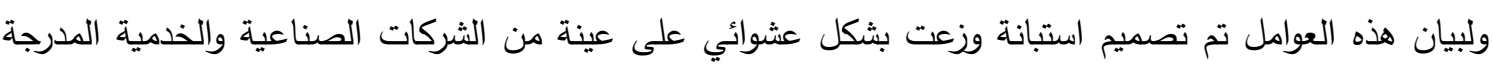
في سوق عمان المالي بلغ عددها 82 شركة. وقد بينت النتائج أنه لم ثُؤثر محددات الإفصاح (تكلفة إعداد البيانات، واستخدام المعلومات من المنافسين، وتفسيرها بشكل خاطئ، وعدم معرفة الشركة بكل احتياجات مستخدمي المعلومات المالية، والتأخير في نشر القوائم المالية، وقناعة الثركة بعدم الحاجة إلى بيانات معينة) الواردة في الفكر ولئي

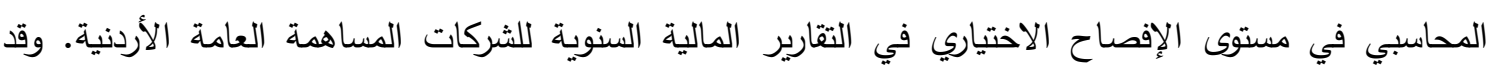

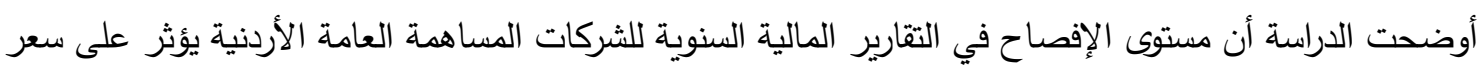
السهم، وكذلك يوثر في الحصول على الإتتمان وكذلك على سمعة الشركة. وبينت الدراسة أن الإفصاح يعزز قيام الإنة

مجلس الإدارة بمسؤولياته، ويُكِّن المساهمين من الحكم على ربحية ومركز الثركة المالي، ويحد من الإثاعات.

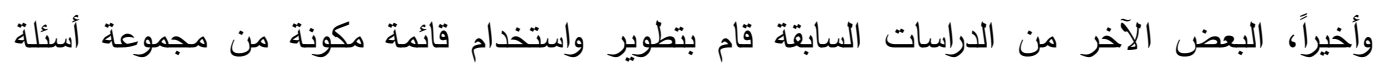

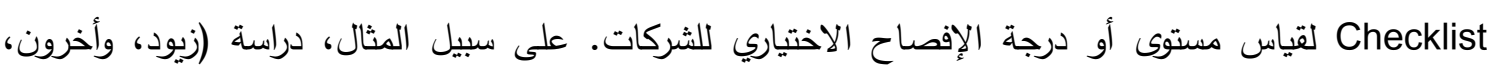

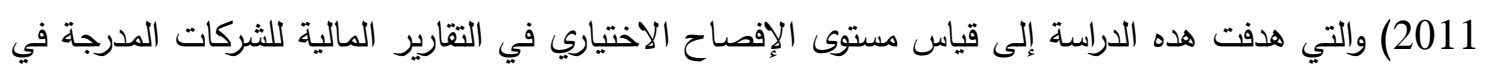

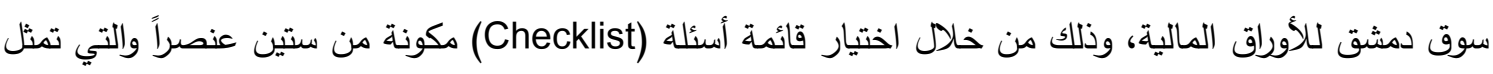
العناصر الأساسية للإفصاح الاختياري. حيث تكونت عينة الدراسة من 15 شركة مدرجة في سوق دمثق للأوراق

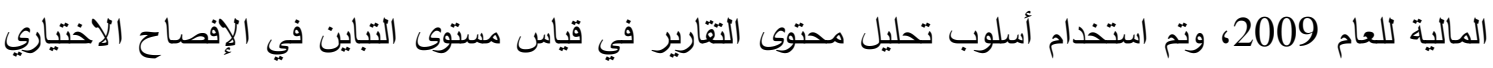

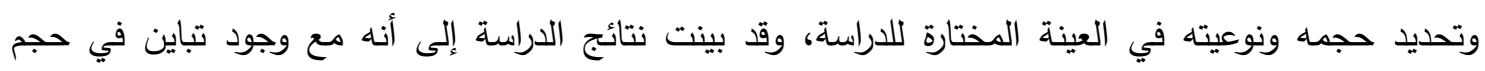

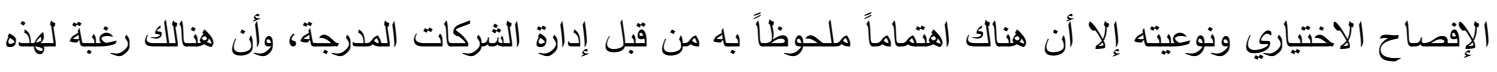

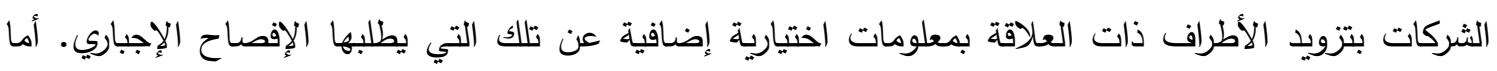
دراسة (مارق، 2009) فقد أجريت لقياس كمية الإفصاح الاختياري ونوعيته في التقارير السنوية للشركات المساهمة السعودية خلال العام 2005، حيث بلغت عينة الدراسة 52 شركة مساهمة سعودية. واستخدمت أيضاً قائمة 
لمجموعة من الأسئلة (Checklist) وذلك لتحليل حجم ونوعية الإفصاح الاختياري في الشركات المساهمة السعودية

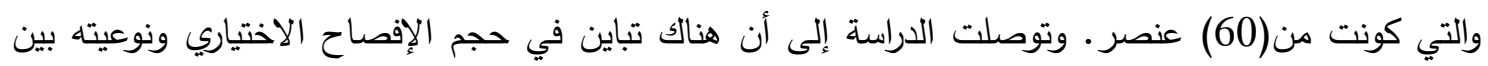

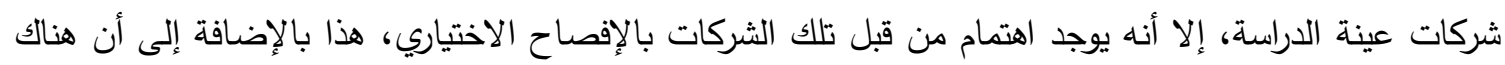

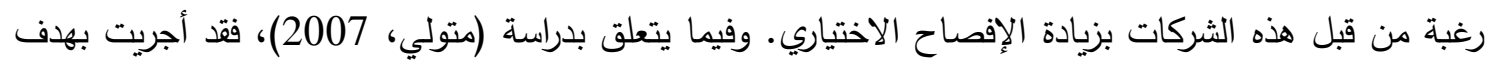

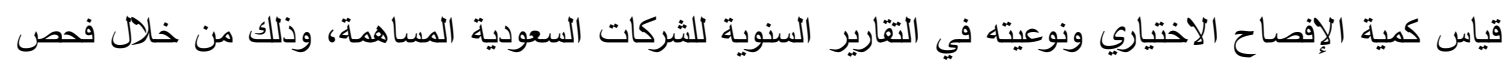
التقارير السنوية المنشورة للعام 2005 وذلك باستخدام كذلك قائمة من الأسئلة لفحص الإفصاح الاختيارياري (Checklist)

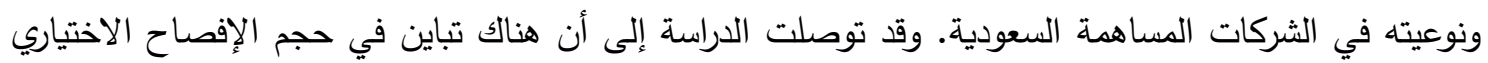

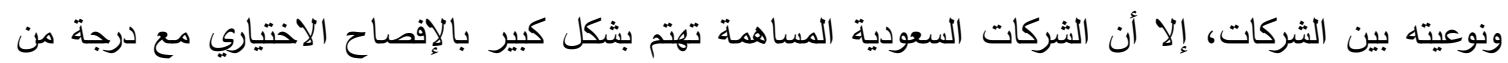
التباين فيما بينها.

ما يميز هذه الاراسة عن الاراسات السابقة من خلال استطلاع الدراسات السابقة تبين أن عدد كبير منها تطرق إلى موضوع الافصاحات الاجبارية وعدد قليل منها تتاول الافصاح الاختياري، وآخر تتاول العوامل التي تؤثر في مستوى الإفصاح في التقارير المالية

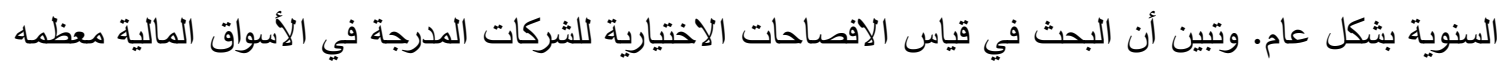

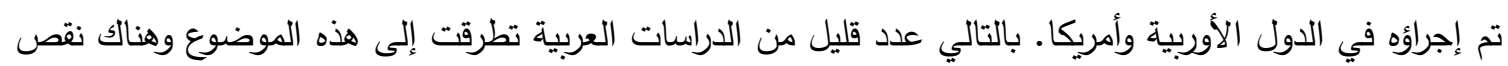

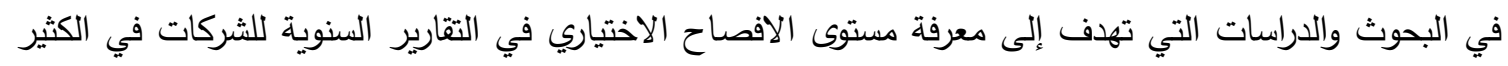
من الدول العربية ومنها فلسطين، لذا تعد هذه الدراسة خطوة أمامية نحو تقديم أداة لقياس مستوى الإفصاح الاختياري وتطبيقه على الثركات المدرجة في بورصة فلسطين، وهذا يعطي دليلاً عن مستوى الإفصاح الاختياري ومدى تطبيقه. وحسب علم الباحثان هذه هي الدراسة الأولى في فلسطين التي تتطرق إلى قياس مستوى الإفصاح

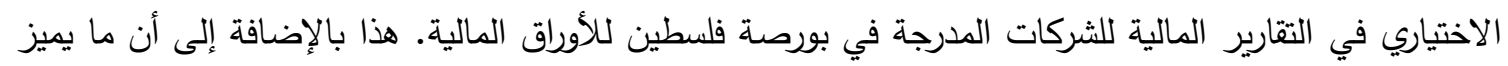
هذه الدراسة أنها لم تكتفي بقياس مستوى الإفصاح الاختياري بل يمتد الأمر لقياس أثر هذا الإفصاح الاختياري

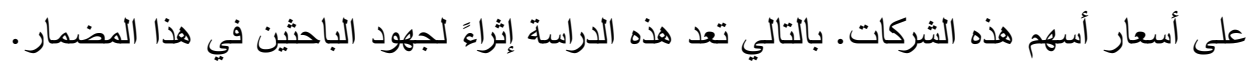
فرضيات الدراسة من خلال الاطلاع على الدراسات السابقة والمتعلقة بعلاقة الإفصاح الاختياري وسعر السهم السوقي

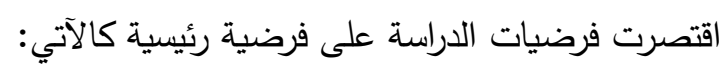
"يوجد أثر ذو دلالة إحصائية لمستوى الافصاح الاختياري لاى الثركات المدرجة في بورصة فلية فلسطين على القيمة السوقية لأسعار أسهمها عند مستوى دلالة 0.05 = 0.

الإطار النظري للاراسة تعريف الإفصاح المحاسبي: الإفصاح المحاسبي هو الذي يلبي احتياجات ومصالح أطراف المشروع، وهو إفصاح يجعل التقارير غير مضللة وذات كيفية تجعل للتقارير قيمة إعلامية يستطيع مستخدم تلك التقارير الاسترشاد بها واتخاذ قرارات استتاداً عليها (جربوع، 2007). وقد عرف (حمد، 2010) الإفصاح المحاسبي بأنه" إرفاق إيضاحات بالقوائم المالية تتناول إيضاح أو تقصيل المعلومات الخاصة بالبنود الواردة في صلب القوائم المالية أو خارجها، وذلك بهدف ألا تكون 
القوائم المالية مضللة، ويمكن أن يشمل المفهوم الطرق المحاسبية المستخدمة والأحداث اللاحقة لتاريخ القوائم وتحليلات الإدارة للأحداث الماضية وتتبؤاتها والقوائم المالية الإضافية التي تتعلق بنشاط الشركة ولا يمكن عرضها بكفاية في صلب القوائم المالية. وقد عرفه (صديقي ومرزوقي، 2010) بأنه: "عملية إيصال ونقل المعلومات التي أعدت في مرحلة القياس لمن يستخدمها ويوظفها ويحتاجها، سواء داخل المؤسسة أو خارجها، بحيث يجب مرفي مراعاة

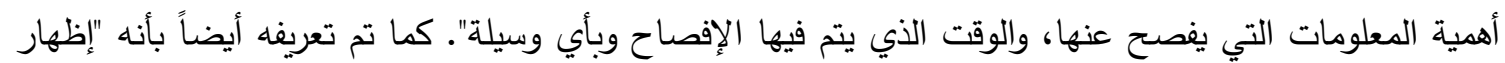
كل المعلومات التي قد تؤثر في موقف متخذ القرار تجاه قرار معين يتعلق بالوحدة المحاسبية، كما يعني أيضا

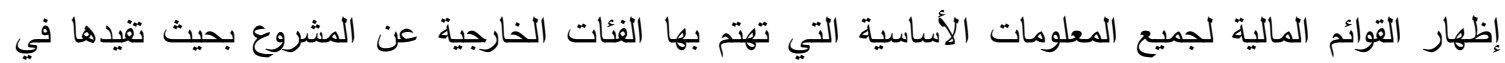
علمية اتخاذ القرار الرشيد (عبد الله، 1995).

ومن هنا يتضح لنا أن الإفصاح المحاسبي يركز على موضوع توصيل المعلومات إلى المستفيدين بهدف بيان حقيقة الوضع المالي للمنشأة دون تضليل بشكل يسمح بالاعتماد على تلك المعلومات في اتخاذ القرارات.

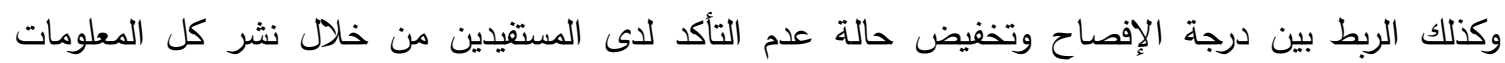
الاقتصادية التي لها علاقة بالمشروع سواء كانت معلومات كمية أو معلومات أخرى تساعد المستثر على اتخاذ

\section{الإفصاح الاختياري وأوجه الاختلاف مع الإفصاح الاجباري}

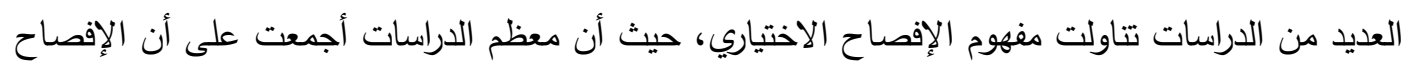

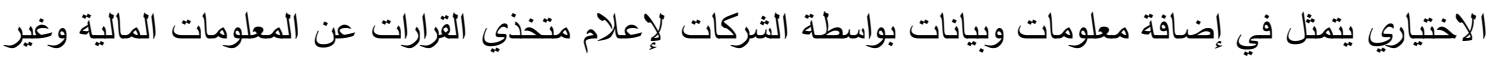

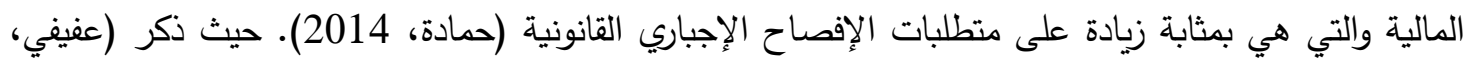

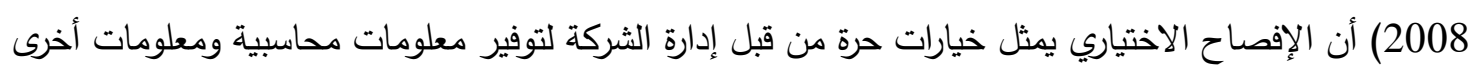

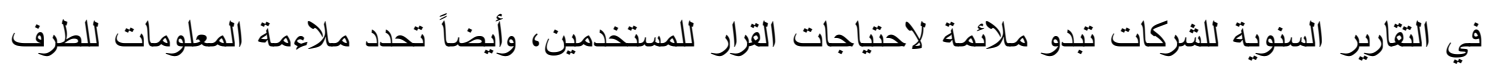
الذي سوف يستخدمها في اتخاذ القرارات. في حين يرى (دحدوح وحمادة، 2015) أن الإفصاح الاختياري يعني تقديم معلومات عن الثركة زيادة على المتطلبات المهنية والقانونية والتتظيمية والاجبارية وهو خيارات حرة من قبل إدارة الثركة تبدو ملائمة للأطراف الخارجية، وكذلك هو معلومات مالية وغير مالية تتعلق بأصحاب القرار .

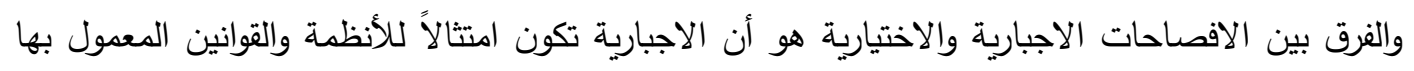

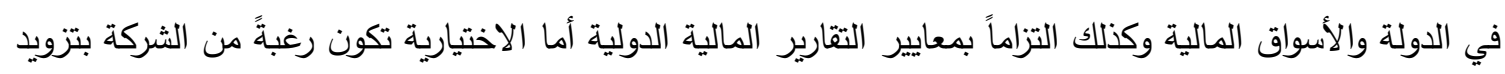
المستخدمين للقوائم المالية والجهات ذات العلاقة بمعلومات إضافية قد تكون مفيدة لهم في اتخاذ قراراتهم الحالية والمستقبلية وفي دراسة الوضع الإداري والمالية للشركات وفي رسم التوجهات المستقبلية. أهداف الإفصاح الاختياري

يسعى الإفصاح بثكل رئيس إلى تلبية احتياجات مستخدمي التقارير المالية كلها من أجل المساعدة في

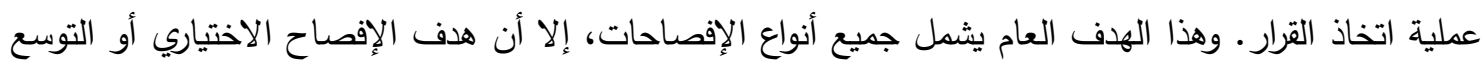
في الإفصاح سوف يمكن المستخدمين من اتخاذ قرارات أكثر دقة وموضوعية، مع العلم بأن التوصية رقم 105

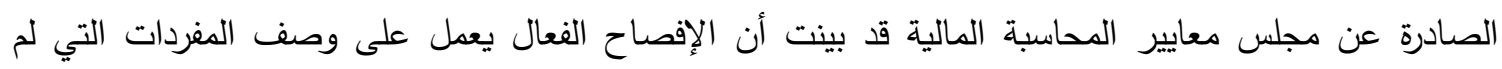

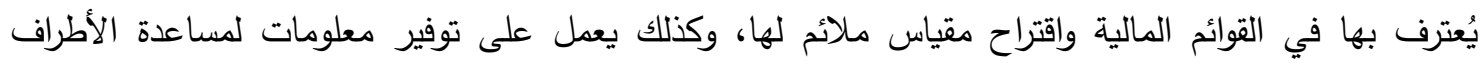
الخارجية على تقدير المخاطر، والعمل أيضاً على توفير معلومات مهمة في التقارير المرحلية، وأي أمور محاسبية أخرى تستلزم دراسة بثكل عام (دحدوح وحمادة، 2015). 
إجراءات الدراسة

منهجية الاراسة

قد اتبعت الدراسة المنهج الاستقرائي وأسلوب تحليل المحتوى في تحليل حجم الإفصاح الاختياري ونوعيته لاى الثركات المساهمة المدرجة في بورصة فلسطين، حيث تم إجراء التحليل على التقارير السنوية المنشورة لها

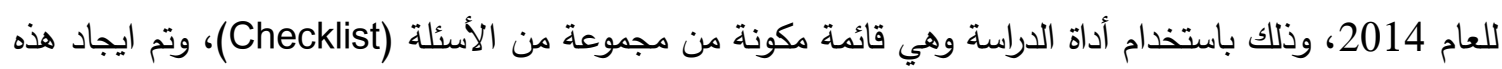

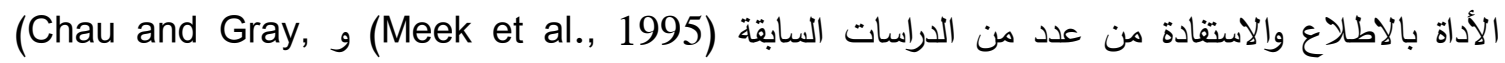
(2002 و (دحدوح وحمادة، 2015)، وتعديلها بما يتلائم مع البيئة الفلسطينية، حيث تكونت القائعة المقترحة من

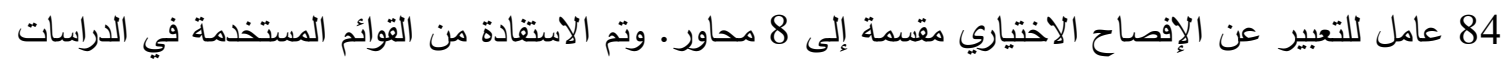

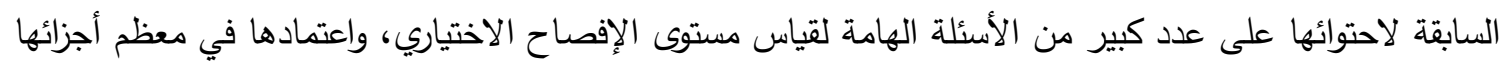

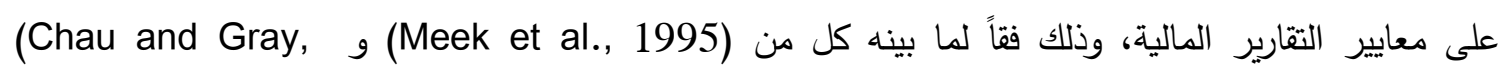

هذا بالإضافة إلى أن الدراسة استخدمت أسلوب تحليل الانحدار لبيان أثر مستوى الإفصاح الاختياري في

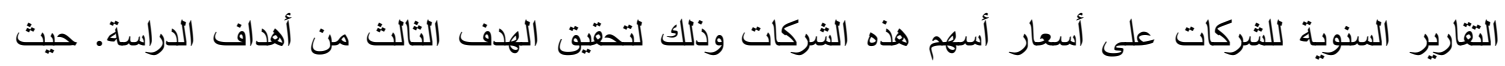
تمثل متغير الدراسة المستقل بمستوى الافصاح الاختياري للشركات والمتغير التابع تمثل في أسعار الأسهم لهذه الثركات في نهاية السنة المالية. مجتمع الاراسة

يتكون مجتمع الدراسة من جميع الثركات المساهمة العامة المدرجة في بورصة فلسطين للأوراق المالية

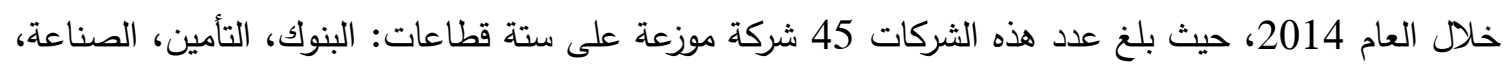
الخدمات، العقارات والاتصالات وتكنولوجيا المعلومات. التحليل الاحصائي ومناقشة النتائج: القسم الأول: قياس مستوى تطبيق الإفصاح الاختياري

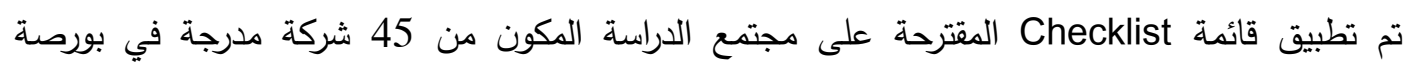
فلسطين للأوراق المالية كما هو موضح في الجدول رقم 1 ، حيث تم الحصول على التقارير المالية لكافة لهذه الشركات من موقع بورصة فلسطين للأوراق المالية للعام 2014، حيث مثل عدد الثركات في قطاع الصناعة العدد

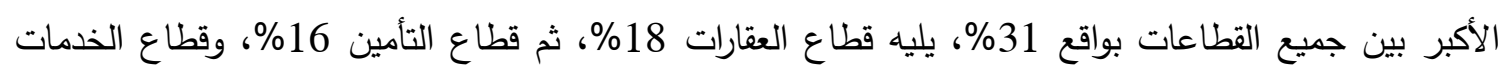

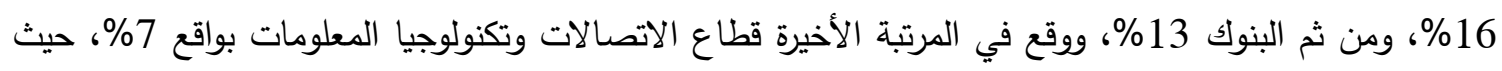

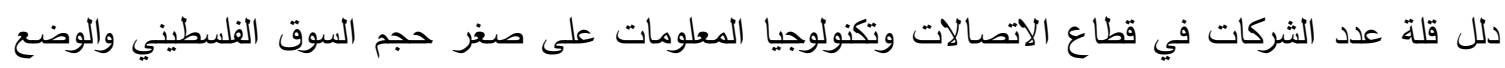
الاقتصادي المتردي في المناطق الفلسطينية. جدول (1): عدد الشركات ونسبة تمثيلها في مجتمع الدراسة

\begin{tabular}{|c|c|c|}
\hline نسبة تمثيل للشركات للمجتمع & عدد الثركات بالمجتمع & القطاع \\
\hline $13 \%$ & 6 & قطاع البنوك \\
\hline $16 \%$ & 7 & قطاع التأمين \\
\hline $16 \%$ & 7 & قطاع الخدمات \\
\hline
\end{tabular}




\begin{tabular}{|c|c|c|}
\hline نسبة تمثيل للشركات للمجتمع & عدد الثركات بالمجتمع & القطاع \\
\hline $31 \%$ & 14 & قطاع الصناعة \\
\hline $18 \%$ & 8 & قطاع العقارات \\
\hline $7 \%$ & 3 & قطاع الاتصالات وتكنولوجيا المعلومات \\
\hline $100 \%$ & 45 & الاجمالي \\
\hline
\end{tabular}

وتم استخدام القائمة المقترحة المكونة من 84 سؤال وموزعة على 8 مجموعات كما هو موضح في ملحق

الدراسة رقم(1)، حيث تم التعبير عن وجود الإفصاح الاختياري للبنود المطلوب الإفصاح عنها في كل شركة

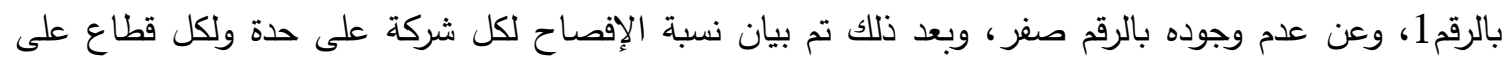

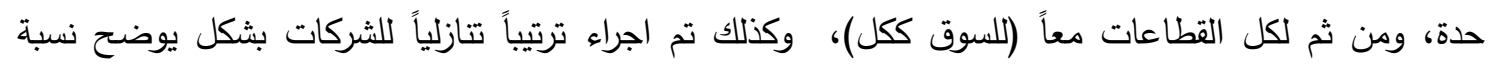

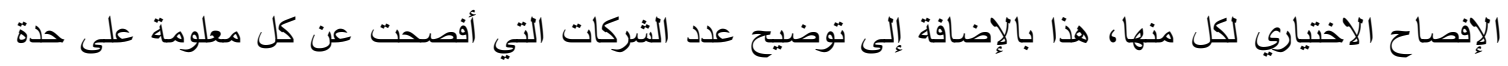

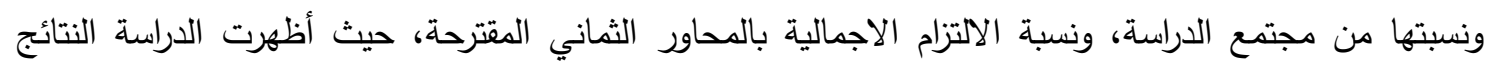

1. قطاع البنوك

يوضح الجدول رقم (2) نسبة الإفصاح الاختياري للبنوك المدرجة في بورصة فلسطين، حيث يدلل التحليل

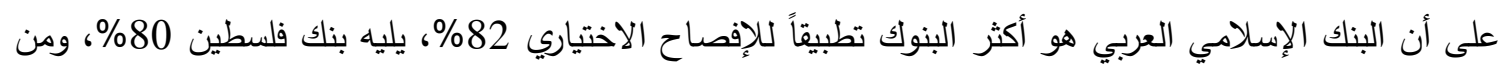

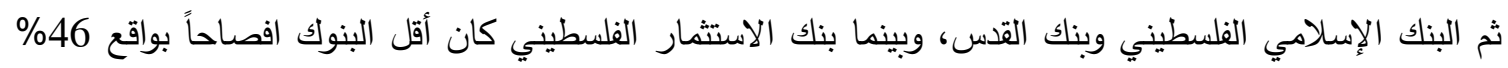
فقط. وهذا يدلل على أن كبرى البنوك العاملة في فلسطين والمدرجة في بورصة فلسطين تسعى إلى زيادة مستوى الإفصاح الاختياري. جدول (2): نسبة الإفصاح الاختياري لقطاع البنوك

\begin{tabular}{|c|c|c|c|c|c|c|}
\hline 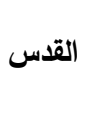 & الاسبلامي & الفلسطيني & الفلسطيني & الفلسطيني & 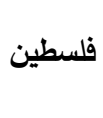 & بيان \\
\hline 17 & 18 & 17 & 9 & 12 & 18 & عدد مفردات المعلومات المفصح عنها اختيارياً \\
\hline 84 & 84 & 84 & 84 & 84 & 84 & عدد الدفردات الاختيارية في القائمة \\
\hline $79 \%$ & $82 \%$ & $79 \%$ & $46 \%$ & $57 \%$ & $80 \%$ & نسبة الإفصاح (\%) \\
\hline
\end{tabular}

ملاحظة: نسبة الإفصاح لكل بنك تم احتسابها بقسمة عدد المفردات المفصح عنها اختيارياً على إجمالي عدد

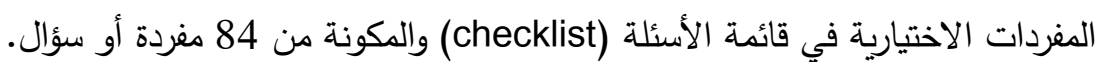

2. قطاع التأمين

يوضح الجدول رقم (3) نسبة الإفصاح الاختياري لشركات التأمين المدرجة في بورصة فلسطين، حيث الإنين

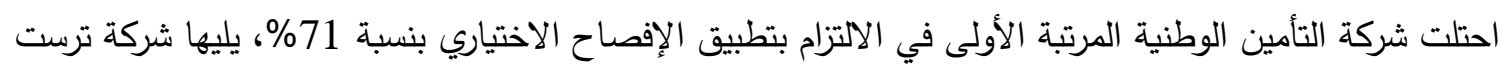

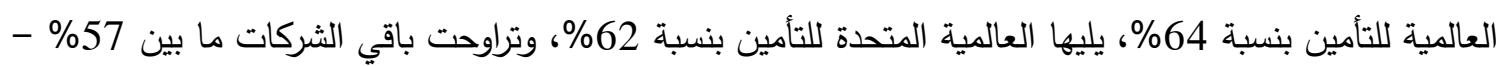
52\%، ومن المعروف أن هذه شركة التأمين الوطنية وشركة ترست للتأمين والمتحدة للتأمين هي من كبرى الثركات

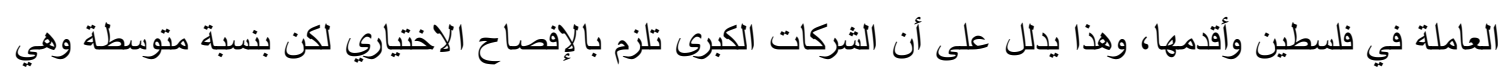
بحاجة إلى التعزيز في هذا الجانب. 
جدول (3): نسبة الإفصاح الاختياري لقطاع شركات التأمين

\begin{tabular}{|c|c|c|c|c|c|c|c|}
\hline اللتأمين & تلترست & اللتأمين & فلتأمينين & للتأمين & الوطنية & للتامين & بيان \\
\hline 45 & 54 & 52 & 48 & 44 & 60 & 35 & عدد مفردات المعلومات المفصح عنها اختيارياً \\
\hline 84 & 84 & 84 & 84 & 84 & 84 & 84 & عدد المفردات الاختيارية في القائمة \\
\hline $54 \%$ & $64 \%$ & $62 \%$ & $57 \%$ & $52 \%$ & $71 \%$ & $42 \%$ & نسبة الإفصاح (\%) \\
\hline
\end{tabular}

ملاحظة: نسبة الإفصاح لكل شركة تم احتسابها بقسمة عدد المفردات المفصح عنها اختيارياً على إجمالي عدد الإسات المفردات الاختيارية في قائمة الأسئلة (checklist) والمكونة من 84 مغردة أو سؤال.

3. قطاع الخدمات

أما فيما يتعلق بقطاع الخدمات، يوضح الجدول رقم (4) أن مستشفى نابلس التخصصي يلتزم بالإفصاح

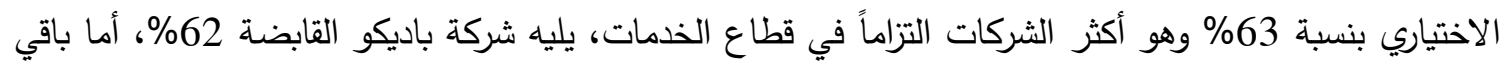

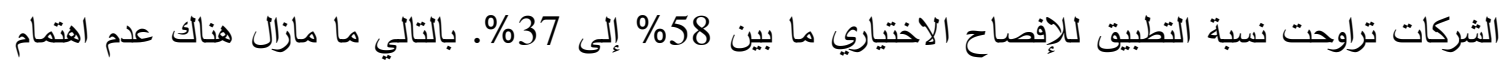

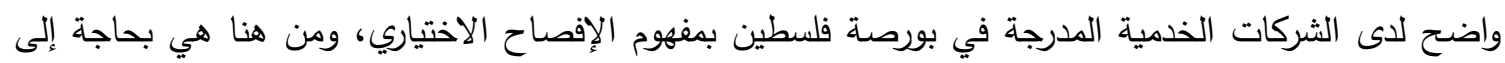

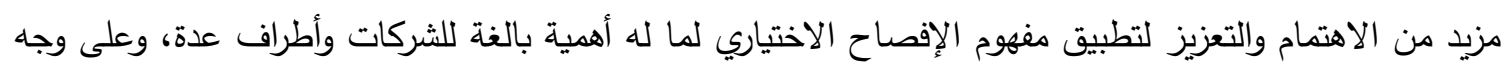
الخصوص الثركة العربية لمراكز التسوق والفلسطينية للكهرباء. جدول (4): نسبة الإفصاح الاختياري لقطاع الخدمات

\begin{tabular}{|c|c|c|c|c|c|c|c|}
\hline سلسط & للفنادبية & التراكز & مجموعة & اللكهرباء & القابضة & مستشفى & 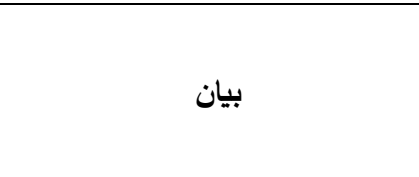 \\
\hline 49 & 42 & 31 & 48 & 36 & 52 & 53 & عدد مفردات المعلومات المفصح عنها \\
\hline 84 & 84 & 84 & 84 & 84 & 84 & 84 & عدد الدفردات الاختيارية في القائية \\
\hline $58 \%$ & $50 \%$ & $37 \%$ & $57 \%$ & $43 \%$ & $62 \%$ & $63 \%$ & نسبة الإفصاح (\%) \\
\hline
\end{tabular}

ملاحظة: نسبة الإفصاح لكل شركة تم احتسابها بقسمة عدد المفردات المفصح عنها اختيارياً على إجمالي عدد المفردات الاختيارية في قائمة الأسئلة (checklist) والمكونة من 84 مفردة أو سؤال.

\section{4. ق قطاع الصناعة}

جدول رقم (5) يوضح نسبة الإفصاح الاختياري للشركات الصناعية المدرجة في بورصة فلسطين، حيث يبين أن شركة مطاحن القهح الذهبي هي الأكثر تطبيقاً للإفصاح الاختياري بنسبة 80\%، يليها شركة فلسطين للاستثمار الصناعي بنسبة 70\%، ومن ثم دواجن القدس بنسبة 68\%، وباقي الثركات الـ 7 تراوحت نسبة التزامها

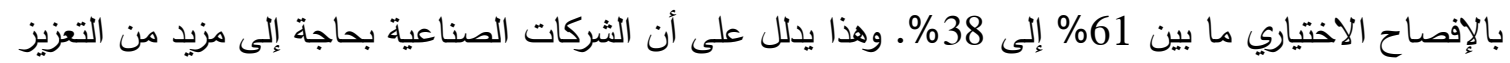

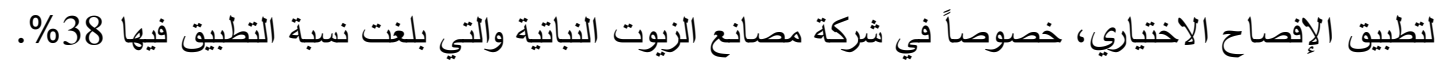


جدول (5): نسبة الإفصاح الاختياري لقطاع الصناعة

\begin{tabular}{|c|c|c|c|c|c|c|c|}
\hline $\begin{array}{c}\text { الإفصاح } \\
\text { (\%) }\end{array}$ & الاختيارية في المفردات & المعلد مفردات & بيان بي & $\begin{array}{c}\text { الإضصباح } \\
\text { (\%) }\end{array}$ & الاختيارية في المفردات & المعلد مفردات & بيان \\
\hline $70 \%$ & 84 & 59 & فلسطين للاستثمار الصناعي & $44 \%$ & 84 & 37 & نابكو \\
\hline $38 \%$ & 84 & 32 & مصانع الزيوت النباتية & $55 \%$ & 84 & 46 & الوطنية لصناعة الكرتون \\
\hline $61 \%$ & 84 & 51 & القدس للمستحضرات الطبية & $42 \%$ & 84 & 35 & مصنع الشرق للإلكترونيات \\
\hline $7 \%$ & 84 & 6 & بيت جالا لصناعة الأدوية & $80 \%$ & 84 & 40 & مطاحن القصح الذهبي \\
\hline $60 \%$ & 84 & 50 & بيرزيت للأدوية & $55 \%$ & 84 & 37 & ايبك \\
\hline $45 \%$ & 84 & 38 & فلسطين لصناعة اللدائن & $68 \%$ & 84 & 67 & دواجن فلسطين \\
\hline $52 \%$ & 84 & 44 & العربية لصناعة الدهانات & $45 \%$ & 84 & 46 & سجاير القس \\
\hline
\end{tabular}

ملاحظة: نسبة الإفصاح لكل شركة تم احتسابها بقسمة عدد المفردات المفصح عنها اختيارياً على إجمالي عدد

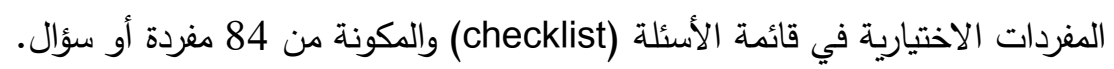
5. قطاع العقارات

يوضح الجدول رقم (6) نسبة الإفصاح الاختياري للشركات العقارية المدرجة في بورصة فلسطين

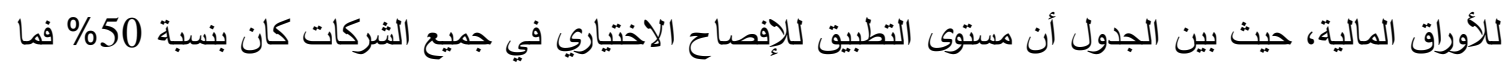
أقل، وهذا مستوى غير مقبول وبحاجة إلى مزيد من التعزيز والاهتمام من قبل هذه الثركات العقارية.

جدول (6): نسبة الإفصاح الاختياري لقطاع العقارات

\begin{tabular}{|c|c|c|c|c|c|c|c|c|}
\hline لـلإعمار & المستثمرون & اللاستثمار & أواجنية & للاستثمار العقارية & عقار & المؤسسة العربة & للاستثمارات القدس & بيان بي \\
\hline 34 & 23 & 21 & 42 & 32 & 33 & 29 & 17 & عدد مفردات المعلومات \\
\hline 84 & 84 & 84 & 84 & 84 & 84 & 84 & 84 & 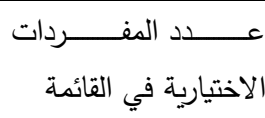 \\
\hline $40 \%$ & $27 \%$ & $25 \%$ & $50 \%$ & $38 \%$ & $39 \%$ & $35 \%$ & $20 \%$ & نسبة الإفصاح (\%) \\
\hline
\end{tabular}

ملاحظة: نسبة الإفصاح لكل شركة تم احتسابها بقسمة عدد المفردات المفصح عنها اختيارياً على إجمالي عدد المفردات الاختيارية في قائمة الأسئلة (checklist) والمكونة من 84 مفردة أو سؤال. 6. قطاع الاتصالات وتكنولوجيا المعلومات

جدول رقم (7) يوضح الإفصاح الاختياري لشركات الاتصالات وتكنولوجيا المعلومات المدرجة في بورصة

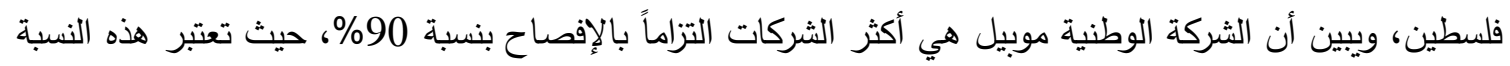
مرتفعة جداً مقارنةً مع باقي الشركات في نفس القطاع ومقارنةً مع القطاعات الأخرى، على الرغم من أنها أنثأت في عام 2006 وتم إدراجها حديثاً في بورصة فلسطين عام 2012، وقد يرجع نسبة ارتفاع نسبة التطبيق للإفصاح 
الاختياري لايها في أنها أنثأت بالشراكة مع شركة كيوتل القطرية، التي تملك نحو 57\% من أسهها، بالإضافة إلى صندوق الاستثمار الفلسطيني الذي يملك 43\%، بالتالي يدلل هذا على أن هناك ادراكاً لدى هذه الشركات المالكة لأهمية الإفصاح الاختياري.

بينما الشركة الأقدم في التأسيس والادراج شركة مجموعة الاتصالات الفلسطينية وهي شركة قابضة تتبع لها العديد من الثركات الهامة في فلسطين منها شركة الهاتف الثابت والجوال الفلسطيني وباديكو وغيرها... انخفضت الته نسبة التطبيق فيها بشكل ملحوظ إلى 58\%، وهذا يدعو إدارة هذا الشركات إلى الاهتمام بالإفصاح الاختياري

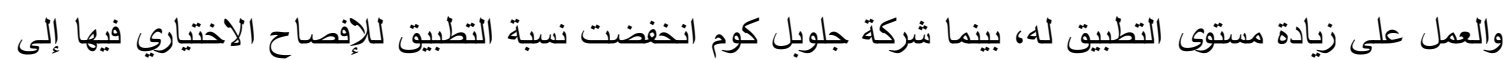
أدنى حد مكن وهو 27\%، وهذا يستدعي إدارة بورصة فلسطين بمطالبة الثركة بمزيد من الإفصاح الاختياري عن

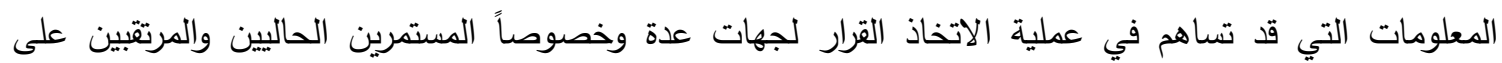
الصعيد المحلي والدولي.

جدول (7): نسبة الإفصاح الاختياري لقطاع الاتصالات وتكنولوجيا المعلومات

\begin{tabular}{|c|c|c|c|}
\hline جلوبال كوم & الوطنية موبايل & مجموعة الاتصالات & 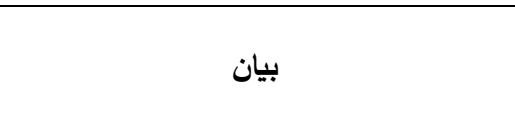 \\
\hline 23 & 76 & 49 & عدد مغردات المعلومات المفصح عنها اختيارياً \\
\hline 84 & 84 & 84 & عدد المفردات الاختيارية في القائمة \\
\hline $27 \%$ & $90 \%$ & $58 \%$ & نسبة الإفصاح (\%) \\
\hline
\end{tabular}

ملاحظة: نسبة الإفصاح لكل شركة تم احتسابها بقسمة عدد المفردات المفصح عنها اختيارياً على إجمالي

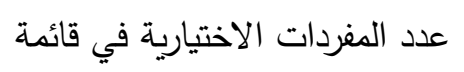

الأسئلة (checklist) والمكونة من 84 مفردة أو سؤال.

7. نسب الإفصاح الاختياري لكل قطاع على حدة ولإجمالي القطاعات: الجدول رقم (8) يوضح نسبة الإفصاح الاختياري لكل قطاع من الشركات المدرجة في بورصة فلاجميارئ فلسطين،

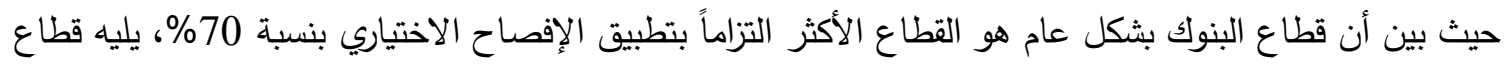

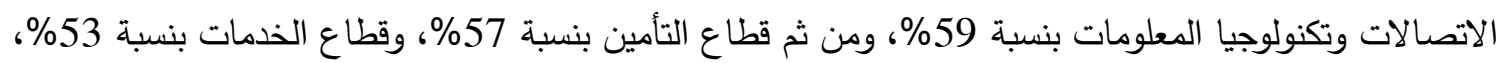
وقطاع الصناعة بنسبة 48\%، وكان قطاع العقارات أقل القطاعات تطبيقاُ للإفصاح الاختياري. بينما بلغت نسبة التطبيق للإفصاح الاختياري في إجمالي القطاعات (للسوق ككل) 54\%، وهذاعا يدلل بشكل عام على أن الشركات المدرجة ببورصة فلسطين لا تلتزم بشكل كبير بمفهوم الإفصاح الاختياري، وهذه النسبة تعتبر

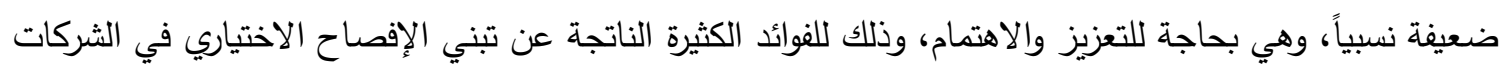
سواء على صعيد الثركات نفسها أم على صعيد المستخدمين لتقاريرها المالية. جلول (8): نسب الإفصاح الاختياري لكل قطاع

\begin{tabular}{|c|c|c|c|}
\hline الاختياري لكل قلطاع الإفصاح & نسبة تمثيل القطاع بالمجتمع & عدد الثركات لكل قطاع & القطاع \\
\hline$\% 70$ & $\% 13$ & 6 & قطاع البنوك \\
\hline$\% 59$ & $\% 7$ & 3 & قطاع الاتصالات وتكنولوجيا \\
\hline$\% 57$ & $\% 16$ & 7 & قطاع التأمين \\
\hline$\% 53$ & $\% 16$ & 7 & قطاع الخدمات \\
\hline
\end{tabular}




\begin{tabular}{|c|c|c|c|}
\hline الاختياري لكل الإفصاح & نسبة تمثيل القطاع بالمجتمع & عدد الثركات لكل قطاع & القطاع \\
\hline$\% 48$ & $\% 31$ & 14 & قطاع الصناعة \\
\hline$\% 36$ & $\% 18$ & 8 & قطاع العقارات \\
\hline$\% 54$ & $100 \%$ & 45 & الاجمالي \\
\hline
\end{tabular}

من خلال ترتيب كافة الشركات المدرجة في بورصة فلسطين حسب نسبة الإفصاح لدى كل شركة وفي جميع القطاعات، الجدول رقم (9) يبين أن أكثر خمس شركات ذات إفصاح اختياري أكبر هي الوطنية موبايل بنسبة 90\%، البنك الإسلامي العربي بنسبة 82\%، بنك فلسطين بنسبة 80\%، شركة مطاحن القـح الذهبي بنسبة 80\% بينما أقل ثلاث شركات ذات افصاح اختياري محدود هي جلوبال كوم بنسبة 27\%، والفلسطينية للاستثمار والانماء بنسبة 25\%، وشركة القدس للاستثمارات العقارية بنسبة 20\%

جدول (9): ترتيب مجتمع الدراسة تنازلياً حسب نسبة الإفصاح لكل شركة

\begin{tabular}{|c|c|c|c|c|c|}
\hline الترتيب & النسبة & اسم الشركة & الترتيب & النسبة & اسم الشركة \\
\hline 23 & $54 \%$ & التكافل للتأمين & 1 & $90 \%$ & الوطنية موبايل \\
\hline 24 & $52 \%$ & المشرق للتأمين & 2 & $82 \%$ & البنك الاسلامي العربي \\
\hline 25 & $52 \%$ & العربية لصناعة الدهانات & 3 & $80 \%$ & بنك فلسطين \\
\hline 26 & $50 \%$ & العربية للفنادق & 4 & $80 \%$ & مطاحن القهـح الذهبي \\
\hline 27 & $50 \%$ & ابراج الوطنية & 5 & $79 \%$ & البنك الاسلامي الفلسطيني \\
\hline 28 & $46 \%$ & بنك الاستثمار الفلسطيني & 6 & $79 \%$ & بنك القدس \\
\hline 29 & $45 \%$ & سجاير القدس & 7 & $71 \%$ & التأمين الوطنية \\
\hline 30 & $45 \%$ & فلسطين لصناعة اللدائن & 8 & $70 \%$ & فلسطين للاستثمار الصناعي \\
\hline 31 & $44 \%$ & شركة نابكو & 9 & $68 \%$ & دواجن فلسطين \\
\hline 32 & $43 \%$ & الفلسطينية للكهرباء & 10 & $64 \%$ & ترست للتأمين \\
\hline 33 & $42 \%$ & الاهلية للتامين & 11 & $63 \%$ & مستثفى نابلس التخصصي \\
\hline 34 & $42 \%$ & مصنع الشرق للالكترونيات & 12 & $62 \%$ & العالمية المتحدة للتأمين \\
\hline 35 & $40 \%$ & الاتحاد للإعمار والاستثمار & 13 & $62 \%$ & باديكو القابضة \\
\hline 36 & $39 \%$ & بال عقار & 14 & $61 \%$ & القدس للمستحضرات الطبية \\
\hline 37 & $38 \%$ & مصانع الزيوت النباتية & 15 & $60 \%$ & بيرزيت للأدوية \\
\hline 38 & $38 \%$ & العقارية التجارية للاستثمار & 16 & $58 \%$ & سوق فلسطين للأوراق المالية \\
\hline 39 & $37 \%$ & الفلسطينية العربية لمراكز التسوق & 17 & $58 \%$ & مجموعة الاتصالات الفلسطينية \\
\hline 40 & $35 \%$ & مؤسسة العقارية العربية & 18 & $57 \%$ & البنك التجاري الفلسطيني \\
\hline 41 & $27 \%$ & المستثرون العرب & 19 & $57 \%$ & فلسطين للتأمين \\
\hline 42 & $27 \%$ & جلوبال كوم & 20 & $57 \%$ & مجموعة واصل \\
\hline 43 & $25 \%$ & الفلسطينية للاستثمار والانماء & 21 & $55 \%$ & الوطنية لصناعة الكرتون \\
\hline 44 & $20 \%$ & القدس للاستثمارات العقارية & 22 & $55 \%$ & إيبك \\
\hline
\end{tabular}


9 9. بيان نسبة الالتزام الاجمالية في المحاور الثماني من قبل الثركات المدرجة

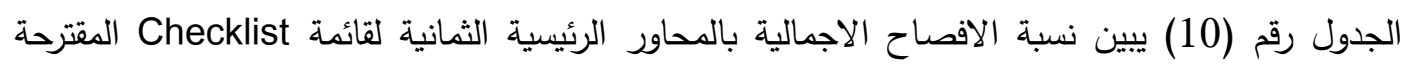

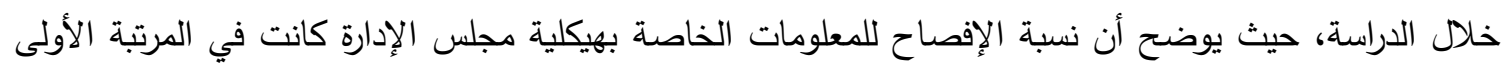
وهي 89\%، أي أن نسبة 89\% من الثركات المدرجة افصحت عن المعلومات الخاصة بهيكلية مجلس الإدارة لديها، بينما بلغت نسبة الشركات التي افصحت عن المعلومات الخاصة بالإدارة العليا 87\%، وكن وكنلك نسبة الشركات

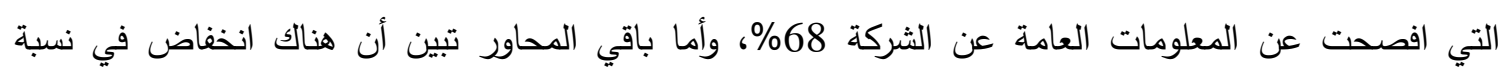
الإفصاح لدى الشركات حيث انخفضت عن 50\%، خاصة فيما يتعلق بنسبة الإفصاح ذات العلاقة بتكاليف البحث والتطوير •

وهذا يدلل على أن هناك عدم اهتمام من قبل الشركات المدرجة في بورصة فلسطين بالافصاحات الاختيارية

الخاصة بالمعلومات عن لجنة التدقيق، وكذلك المعلومات عن العاملين في الثركة والمعلومات الخاصة بالمسؤولية بألية

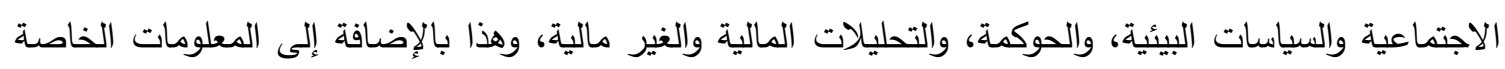

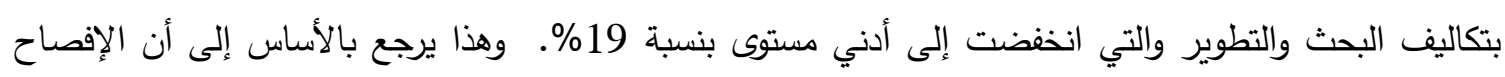

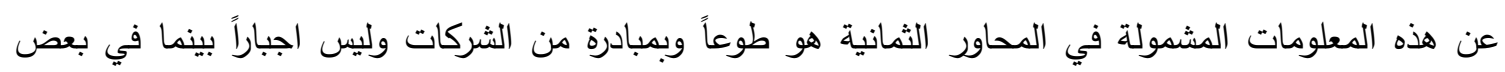

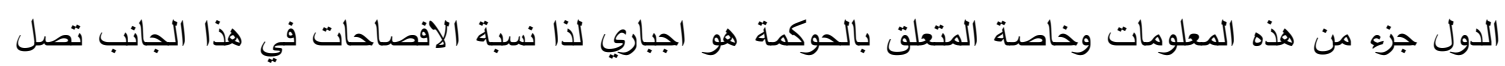
إلى نسبة كبيرة.

\begin{tabular}{|c|c|c|}
\hline نسبة الإفصاح & معلومات الإفصاح الاختياري & b \\
\hline $89 \%$ & الافصاحات الخاصة بهيكلية مجلس الإدارة & 1 \\
\hline $87 \%$ & معلومات عن الإدارة العليا & 2 \\
\hline $68 \%$ & المعلومات العامة عن الشركة & 3 \\
\hline $50 \%$ & معلومات عن لجنة التدقيق & 4 \\
\hline $44 \%$ & معلومات عن العاملين في الشركة وافصاحات عن المسؤولية الاجتماعية والسياسات البيئية & 5 \\
\hline $42 \%$ & معلومات عن الحوكمة & 6 \\
\hline $42 \%$ & افصاحات عن تحليلات مالية وغير مالية & 7 \\
\hline $19 \%$ & تكاليف البحث والتطوير & 8 \\
\hline
\end{tabular}

بناءً على نتائج التحليل الاحصائي أعلاه، يتبين أن هناك اختلاف في مستوى الإفصاح الاختياري

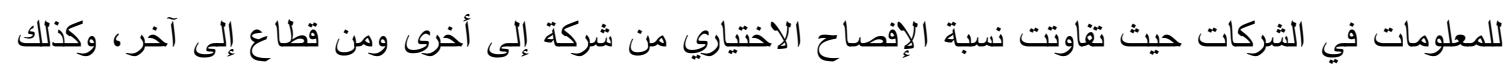

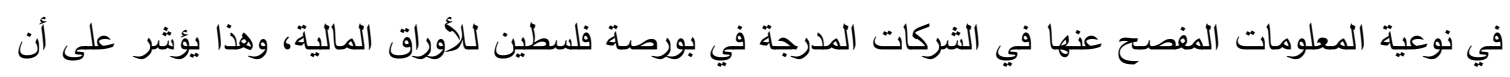
هناك اختلاف وتباين في حجم ونوعية الإفصاح الاختياري للمعلومات بين الثركات المدرجة في بورصة فلهات فلسطين

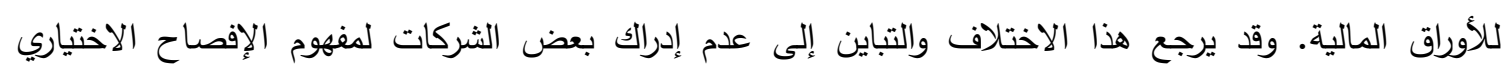

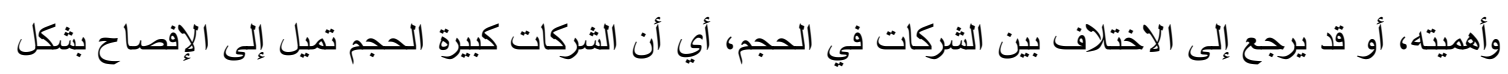

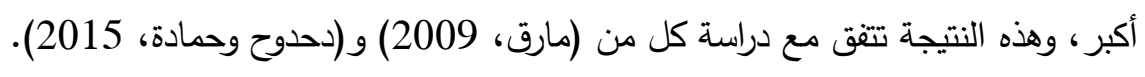


القسم الثاني: قياس تأثير مستوى الإفصاح الاختياري على أسعار الأسهم

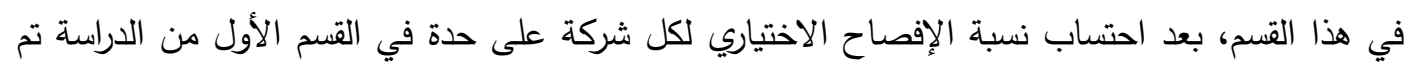

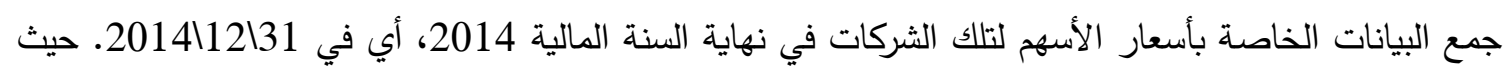
مثل السعر السوقي للسهم المتغير التابع للدراسة وكذلك مثلت نسبة الإفصاح الاختياري لكل شركة المتغير المستقل. وذلك بهدف قياس أثر مستوى هذه الافصاحات الاختيارية على أسعار أسهم هذه الثركات المدرجة في بورصة فلسطين للأوراق المالية خلال العام 2014، حيث تم استخدام نموذج الانحدار الخطي الآتي:

$$
P=\beta_{0}+\beta_{1} D+\varepsilon_{t}
$$

حيث أن: P القيمة السوقية لسعر السهم وهي المتغير التابع P

$$
\begin{aligned}
& \text { D: نسبة الإفصاح } \\
& \text { O }
\end{aligned}
$$

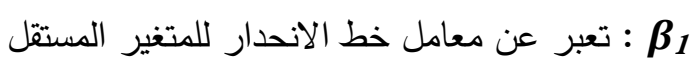
ع : الخطأ العشوائي.

ويجدر الإثارة هنا، أنه تم الحصول على أسعار الأسهم من التقارير المالية المنشورة لبورصة فلسطين

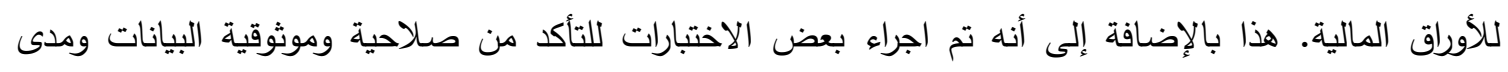

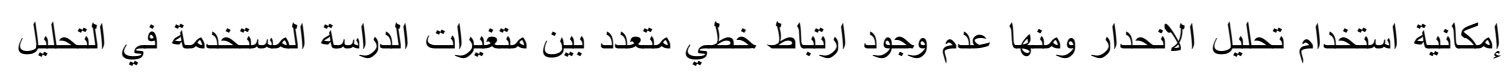

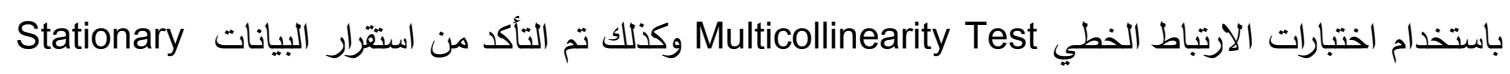
Test Variance Inflation Factors

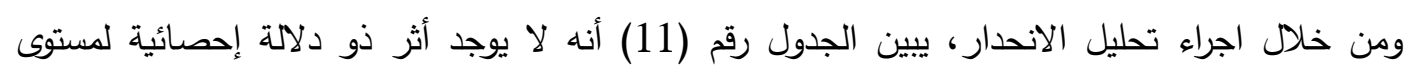

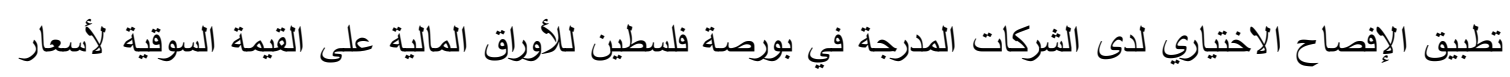

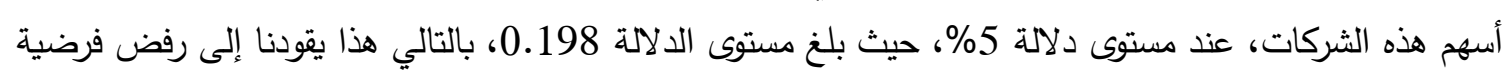
الدراسة الرئيسية والتي نصت على أنه "يوجد أثر ذو دلالة إحصائية لمستوى الافصاح الاختياري لدى الثركات المدرجة في بورصة فلسطين على القيمة السوقية لأسعار أسهمها عند مستوى دلالة

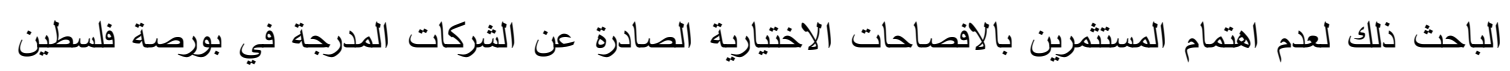

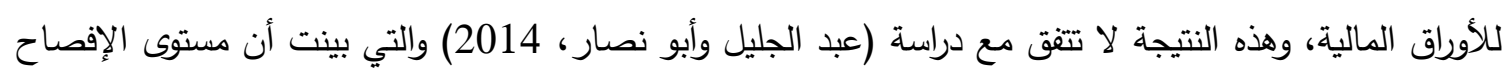

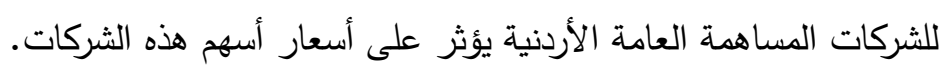


جدول رقم (11): معادلة الاندار: أثر مستوى الإفصاح الاختياري على أسعار أسهم الثركات

\begin{tabular}{|c|c|c|c|c|c|}
\hline \multirow{2}{*}{ Model } & \multicolumn{2}{|c|}{$\begin{array}{c}\text { Unstandardized } \\
\text { Coefficients }\end{array}$} & \multirow{2}{*}{$\begin{array}{c}\begin{array}{c}\text { Standardized } \\
\text { Coefficients }\end{array} \\
\text { Beta }\end{array}$} & \multirow{2}{*}{$\mathbf{t}$} & \multirow{2}{*}{ Sig. } \\
\hline & $B$ & Std. Error & & & \\
\hline $\begin{array}{l}\text { (Constant) } \\
\text { مستوى الافصاح }\end{array}$ & $\begin{array}{l}0.490 \\
0.023\end{array}$ & $\begin{array}{l}0.038 \\
0.017\end{array}$ & 0.196 & $\begin{array}{l}12.942 \\
1.307\end{array}$ & $\begin{array}{l}0.000 \\
0.198\end{array}$ \\
\hline $\mathbf{F}$ & \multicolumn{5}{|l|}{1.709} \\
\hline مستوى الدلالة لـ F & \multicolumn{5}{|l|}{0.198} \\
\hline معامل التحديد (R2) & \multicolumn{5}{|l|}{0.038} \\
\hline معامل التحديد المعدل(R2) & \multicolumn{5}{|l|}{0.016} \\
\hline الخطأ المعياري & \multicolumn{5}{|l|}{0.1752} \\
\hline
\end{tabular}

a. Dependent variable: سعر السهخ

b. $* p<0.05$

النتائتج والتوصيات: أولاً: النتائج

تم التوصل إلى النتائج التالية:

1- تبين أن قطاع البنوك بشكل عام هو القطاع الأكثر التزاماً بتطبيق الإفصاح الاختياري بنسبة 70\%، حيث كان

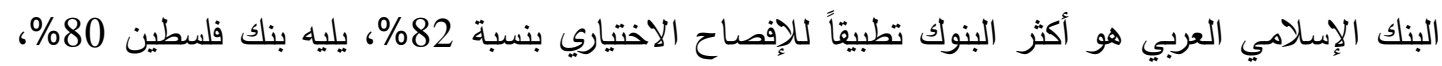

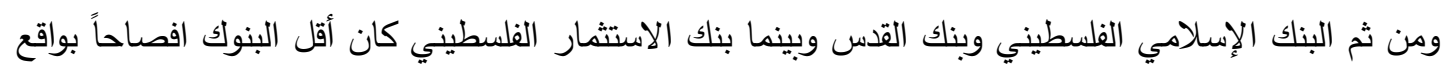

46\% فقط.

2- وجاء في المرتبة الثانية قطاع الاتصالات وتكنولوجيا المعلومات بنسبة 59\%، حيث أن الثركة الوطنية موبيل هي أكثر الشركات التزاماً بالإفصاح بنسبة 90\%، حيث كانت الاتصات ونكولة هذه النسبة مرتفعة جداً مقارنةً مع باقي

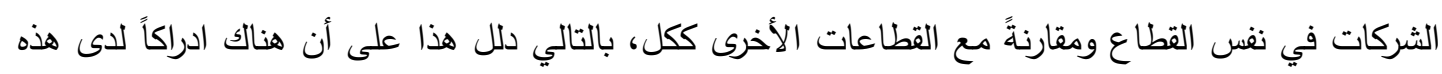

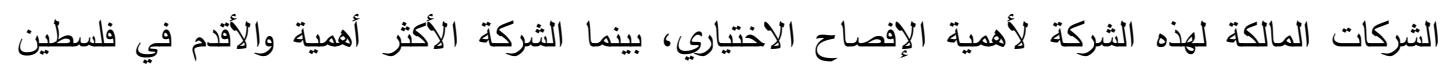

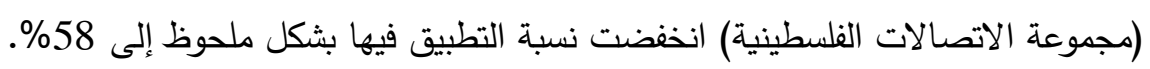
3- وجاء في المرتبة الثالثة قطاع التأمين بنسبة 57\%، حيث احتلت شركة التأمين الوطنية المرتبة الأولى في

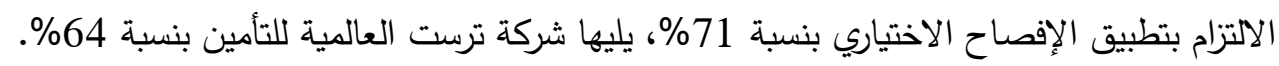

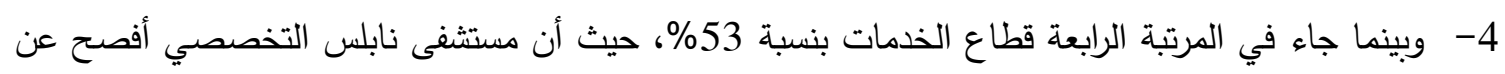

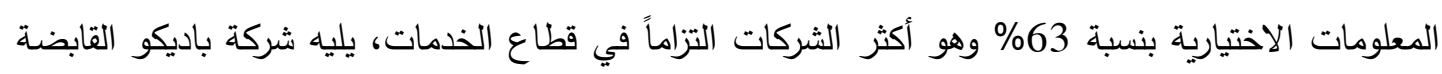

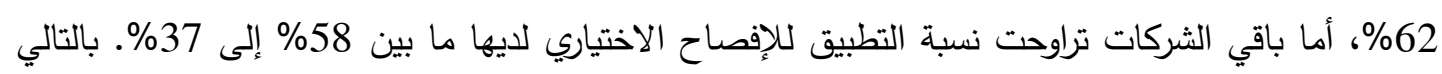
ما مازال هناك عدم اهتمام واضح لاى الثركات الخدمية الدرجة في بورصة فلسطين بمفهوم الإفصاح

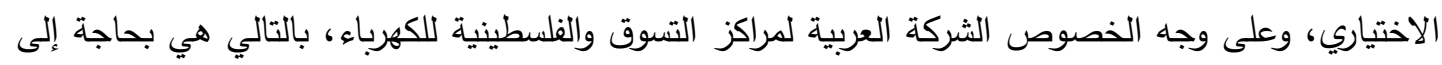

$$
\text { مزيد من الاهتمام والتعزيز لتطبيق مفهوم الإفصاح الاختياري. }
$$

5- وجاء في المرتبة الخامسة قطاع الصناعة بنسبة 48\%، هيث ولتئ تبين أن شركة مطاحن القمح الذهبي هي الأكثر تطبيقاً للإفصاح الاختياري بنسبة 80\%، يليها شركة فلسطين للاستثمار الصناعي بنسبة 70\%ة

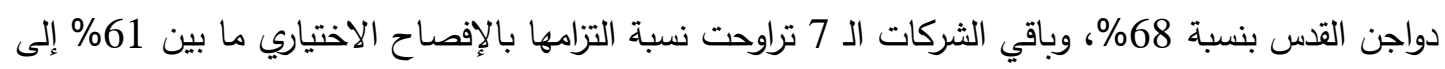


38\% وهذا يؤشر أيضاً على أن الشركات الصناعية بشكل عام بحاجة إلى مزيد من التعزيز لتطبيق الإفصاح

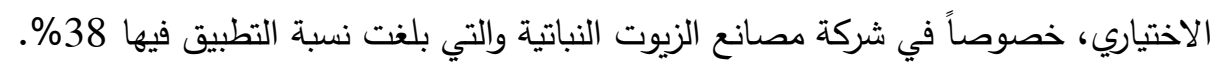

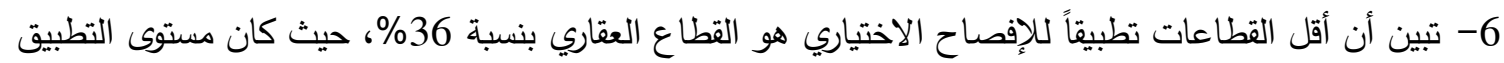

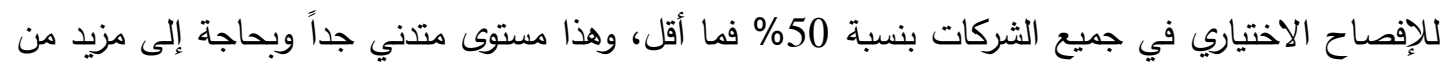
الاهتمام من قبل إدارة هذه الثركات.

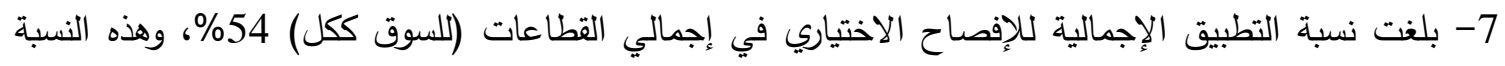

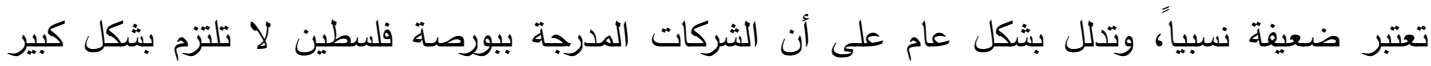

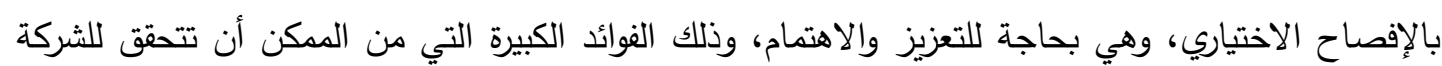
نفسها وللأطراف ذات العلاقة. 8- أن الخمس شركات الأولى ذات أكبر إفصاح اختياري على التوالي هي الوطنية موبايل بنسبة 90\%، البنك

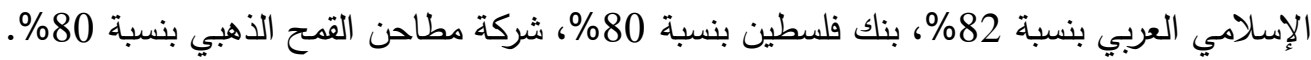
9- تبين أن هناك عدم اهتمام من قبل الثركات المدرجة في بورصة فلسطين بالافصاحات الاختيارية الخاصة

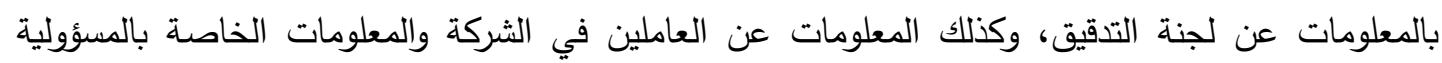
الاجتماعية والسياسات البيئية، والحوكمة، والتحليلات المالية والغير مالية، وهذا بالإضافة إلى المعلومات الخاصة بتكاليف البحث والتطوير • 10-وأخيراً وبشكل عام، تبين أن هناك اختلاف وتباين في حجم ونوعية الإفصاح الاختياري للمعلومات بين

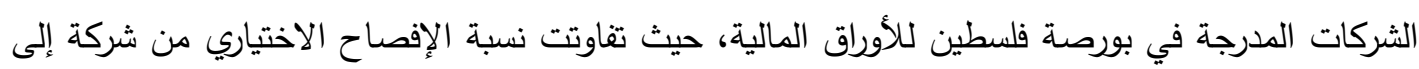

$$
\text { أخرى ومن قطاع إلى آخر . }
$$

11 - لا يوجد أثر ذو دلالة إحصائية لمستوى الإفصاحات الاختيارية لدى الثركات المدرجة في بورصة فلسطين

$$
\text { على القيمة السوقية لأسعار أسهمها عند مستوى دلالة } 0.05 \text { = } 0 .
$$

ثانياً: التوصيات

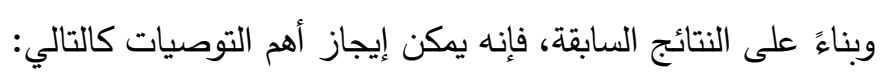

1- ضرورة زيادة مستوى الإفصاح الاختياري لدى الشركات المدرجة في بورصة فلسطين للأوراق المالية، وذلك فلك الكيات

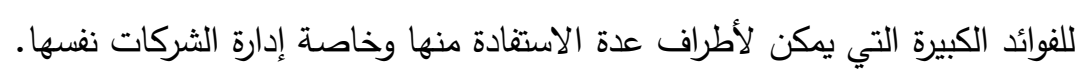

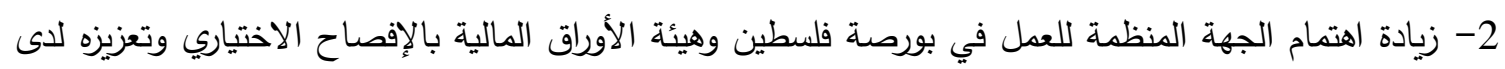
الشركات المدرجة في البورصة، وذلك من خلال القائمة Checklist المقترحة في البحث لتئييم الإفصاح الاختياري في الشركات المدرجة في بورصة فلسطين، وذلك بتثجيع هذه الثركات على الإفصاح الاختياري، وخصوصاً الشركات العقارية والشركات التي انخفض فيها مستوى الإفصاح الاختياري بشكل ملحوظ.

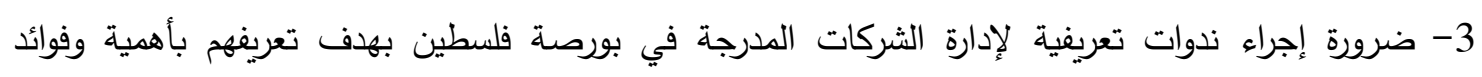
الإفصاح الاختياري للشركة وللأطراف ذات العلاقة ودوره في تحسين جودة التقارير المالية. ثالثاً: مقترحات مستقبلية 1- دراسة العوامل التي تؤثر على الافصاحات الاختيارية في الشركات المدرجة في بورصة فلسطين للأوراق المالية. 
2- دراسة أثر مستوى حوكمة الشركات على مستوى الافصاحات الاختيارية لاى الشركات المدرجة في بورصة فلسطين للأوراق المالية.

أبو شلوع، هديل. (2013). محددات الإفصاح المحاسبي الاختياري في شركات المساهمة دراسة نظرية وميدانية

في بيئة الأعمال المصرية. رسالة ماجستير في المحاسبة غير منشورة. كلية التجارة، جامعة طنطا.

جربوع، يوسف. (2007). مدى تطبيق القياس والافصاح المحاسبي عن المسؤولية الاجتماعية بالقوائم المالية في الثركات بقطاع غزة. مجلة الجامعة الإسلامية. المجلد 15، العدد 1: 239-281.

حمادة، رشا. (2014). قياس أثر الإفصاح الاختياري في جودة التقارير المالية - دراسة ميدانية في بورصة

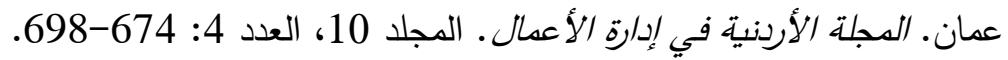

حمد، محمد. (2010). دور الإفصاح المحاسبي وأهميته في ظل تطبيق معايير المحاسبة المصرية ومتطلبات

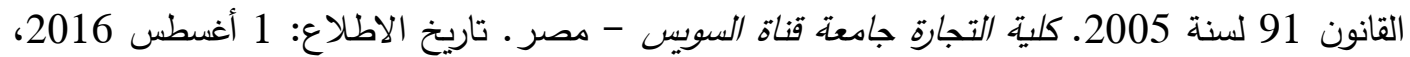
http://www.acc4arab.com:الموقع الخيال، توفيق عبد المحس. (2009). الإفصاح الاختياري ودوره في ترشيد الترارات الاستثارية في السوق المالي السعودي: دراسة ميدانية. المجلة العلية للاقتصاد والتجارة. العدد 3 :105- 156. دحدوح، حسين، حمادة، رشا. (2005). نموذج مقترح لقياس الإفصاح الاختياري وتطبيقه في بيئة الأعمال

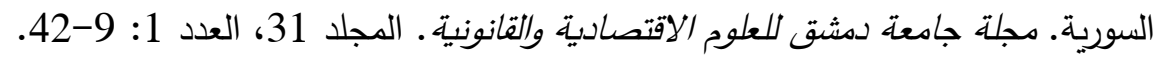
زيود، لطيف، العثمان، محمد، علي، ريم. (2011). مستوى الإفصاح الاختياري في التقارير المالية المنشورة للشركات المساهمة المسجلة في سوق دمشق للأوراق المالية. مجلة جامعة تشرين للبحوث والدراستات الإستات

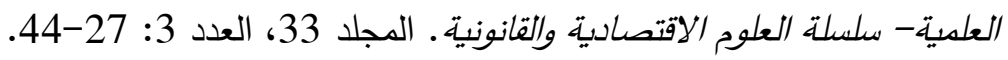
العاني، حارس. (2005). دور المعلومات المحاسبية في قياس وتقييم الأداء الاجتماعي للمؤسسات الصناعيةدراسة تطبيقية في مملكة البحرين. المؤتمر العلمي الرابع. جامعة فيلادلفيا، عمان، الأردن. عبد الجليل، حسن، أبو نصار، محمد. (2014). العوامل المؤثرة على مستوى الإفصاح الاختياري في التقارير

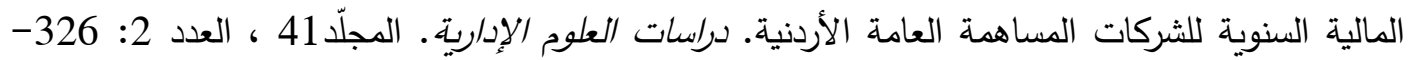

عبد الله، خالد أمين. (1995). الإفصاح ودوره في تتشيط التداول في أسواق رأس المال العربية، الدحاسب القانوني العربي. العدد92 : 38-40.

عفيفي، هلال عبد الفتاح. (2008). العلاقة بين تطبيق حوكمة الشركات ومستوى الإفصاح الاختياري في التقارير

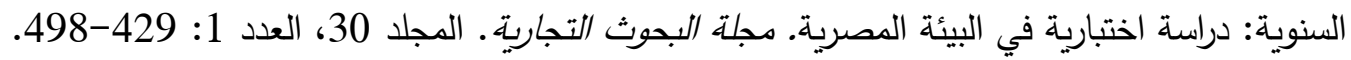
مارق، سعد محمد. (2009). قياس مستوى الإفصاح الاختياري في التقارير المالية المنشورة للشركات المساهمة السعودية، مجلة جامعة الملك عبد العزيز. المجلد،23، العدد 1: 131-174. متولي، طلعت عبد العظيم. (2007). نموذج مقترح لقياس حجم ونوعية الإفصاح الاختياري بالتطبيق على بيئة

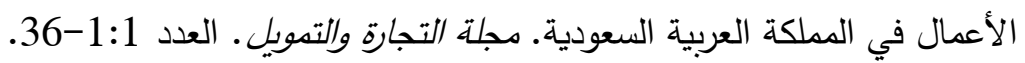




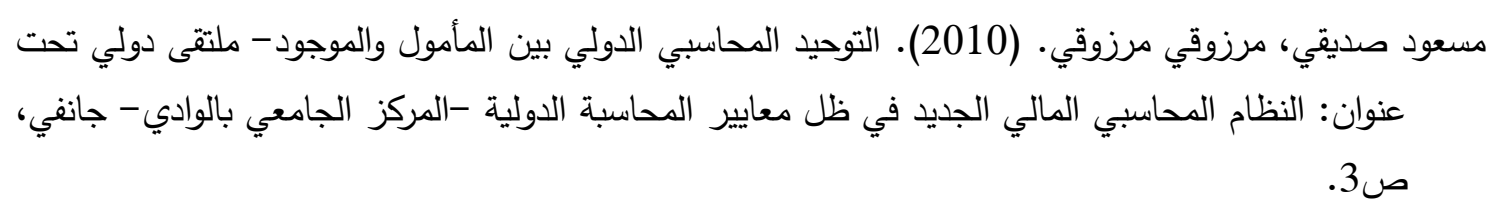

\section{References}

Abdul Jalil, H., \& Abu Nassar, M. (2014). Factors affecting the level of voluntary disclosure in the annual financial reports of Jordanian public joint-stock companies. Administrative Science Studies, 41(2), 326-342. (in Arabic)

Abdullah, K. (1995). Disclosure and its role in activating trading in the Arab capital markets. The Arab Accountant, 92, 38-44. (in Arabic)

Abu Shalo, H., (2013). Determinant of voluntary accounting disclosure of public shareholding companies: A theoretical and an empirical study in the Egyptian business environment [Unpublished master thesis]. Tanta University, Egypt. (in Arabic)

Adelopo, I. (2011). Voluntary disclosure practices amongst listed companies in Nigeria. Advances in Accounting, 27(2), 338-345. https://doi.org/10.1016/j.adiac.2011.08.009

Afifi, H. (2008). The relationship between the corporate governance implementation and the level of voluntary disclosure in annual reports: A pilot study in the Egyptian environment. Journal of Business Research, 30(1), 429-498. (in Arabic)

Al Khayal, T. (2009). The voluntary disclosure and its role in rationalizing investment decisions in the Saudi financial market: An empirical study. Scientific Journal of Economics and Trade, 3, 105- 156. (in Arabic)

Alani, H. (2005). The role of accounting information in measuring and evaluating the social performance of industrial institutions: An applied study in the Kingdom of Bahrain [Conference Presentation]. Fourth Scientific Conference, Philadelphia University, Amman, Jordan. (in Arabic)

Alareeni, B. (2018). The impact of firm-specific characteristics on earnings management: Evidence from GCC countries. International Journal of Managerial and Financial Accounting, 10(2), 85-104. https://doi.org/10.1504/IJMFA.2018.10012808

Alareeni, B. (2018). Does corporate governance influence earnings management in listed companies in Bahrain Bourse?. Journal of Asia Business Studies, 12(4), 551-570. https://doi.org/10.1108/JABS-06-2017-0082

Alareeni, B., \& Aljuaidi, O. (2014). The modified Jones and Yoon models in detecting earnings management in Palestine Exchange (PEX). International Journal of Innovation and Applied Studies, 9(4), 1472-1484.

Alareeni, B., \& Branson, J. (2011). The relative performance of auditors' going-concern opinions and statistical failure prediction models in Jordan. Accountancy \& Bedrijfskunde, 31(8), 23-35

Alareeni, B., \& Branson, J. (2013). Predicting listed companies' failure in Jordan using Altman models: A Case Study. International Journal of Business and Management, 8(1), 113. https://doi.org/10.5539/ijbm.v8n1p113

Alareeni, B., \& Deghish, H. (2016). Applicability of the balanced scorecard to assess performance of Al-Aqsa media network institution in Gaza Strip. IUG Journal of Economics and Business, 24 (3), 21-46. https://doi.org/10.12816/0035571

Alqallaf, H., \& Alareeni, B. (2018). Evolving of selected integrated reporting capitals among listed Bahraini banks. Journal of Accounting and Applied Business Research, 1(1), 1-21. https://doi.org/10.51325/ijbeg.v1i1.10 
Awadh, M., \& Alareeni, B. (2018). Measuring level of voluntary disclosures of banks listed in Bahrain Bourse. Journal of Accounting \& Marketing, 7(3), 295. https://doi.org/10.4172/2168-9601.1000295

Bình, T.Q. (2016). Voluntary disclosure information in the annual reports of nonfinancial listed companies: The case of Vietnam. Journal of Applied Economics and Business Research, 2(2), 69-90.

Brief, R. P. (1975). The accountant's responsibility in historical perspective. The Accounting Review, 50(2), 285-297.

Bushman, R. M., \& Smith, A. J. (2001). Financial accounting information and corporate governance. Journal of Accounting and Economics,32(1), 237-333. https://doi.org/10.1016/S0165-4101(01)00027-1

Chau, G. K., \& Gray, S. J. (2002). Ownership structure and corporate voluntary disclosure in Hong Kong and Singapore. The International Journal of Accounting, 37(2), 247-265. https://doi.org/10.1016/S0020-7063(02)00153-X

Cormier, D., Ledoux, M. J., \& Magnan, M. (2012). The moderating effect of voluntary disclosure on the relation between earnings quality and information asymmetry: Some Canadian evidence. International Journal of Accounting, Auditing and Performance Evaluation, 8(2),

157-183. https://doi.org/10.1504/IJAAPE.2012.046706

Dahdouh, H., \& Hamada, R. (2005). A proposed model for measuring and applying voluntary disclosure in the Syrian business environment. Damascus University Journal of Economic and Legal Sciences, 31(1), 9-42. (in Arabic)

Dedman, E., Lin, S. W. J., Prakash, A. J., \& Chang, C. H. (2008). Voluntary disclosure and its impact on share prices: Evidence from the UK biotechnology sector. Journal of Accounting and Public Policy,27(3), 195-216. https://doi.org/10.1016/j.jaccpubpol.2008.02.001

Esfesalari, D., \& Zarei, A. (2013). Studying the effect of voluntary disclosure changes on firm value. European Online Journal of Natural and Social Sciences, 2(3s), 130-136.

Gray, S. J., Meek, G. K., \& Roberts, C. B. (1995). International capital market pressures and voluntary annual report disclosures by US and UK multinationals. Journal of International Financial Management \& Accounting, 6(1), 43-68. https://doi.org/10.1111/j.1467-646X.1995.tb00049.x

Hail, L. (2002). The impact of voluntary corporate disclosures on the ex-ante cost of capital for Swiss firms. European Accounting Review, 11(4), 741-773. https://doi.org/10.1080/0963818022000001109

Hamad, M. (2010). The role and importance of accounting disclosure in light of the application of the Egyptian accounting standards and the requirements of Law 91 for the year 2005. Suez Canal University, Egypt. (in Arabic)

Hamada, R. (2014). Measuring the effect of voluntary disclosure on the quality of financial reports: An empirical study of Amman Stock Exchange. Jordanian Journal of Business Administration, 10(4), 674-698. https://doi.org/10.12816/0025744 (in Arabic)

Hamdan, A., Buallay, A., \& Alareeni, B. (2017). The moderating role of corporate governance on the relationship between intellectual capital efficiency and firm's performance: Evidence from Saudi Arabia. International Journal of Learning and Intellectual Capital, 14(4), 295-318. https://doi.org/10.1504/IJLIC.2017.087377

Healy, P. M., \& Palepu, K. G. (2001). Information asymmetry, corporate disclosure, and the capital markets: A review of the empirical disclosure literature. Journal of 
Accounting and Economics, 31(1), 405-440. https://doi.org/10.1016/S01654101(01)00018-0

Ho, S. S., \& Wong, K. S. (2001). A study of corporate disclosure practice and effectiveness in Hong Kong. Journal of International Financial Management \& Accounting, 12(1), 75-102. https://doi.org/10.1111/1467-646X.00067

Jerboa, Y. (2007). The extent of application of measurement and disclosure in accounting for social responsibility in financial statements in companies in the Gaza Strip. Islamic University Journal, 15(1), 239-281. (in Arabic)

Maraq, S. (2009). Measuring the level of voluntary disclosure in published financial reports of Saudi joint stock companies. King Abdul Aziz University Journal, 23(1), 131-174. https://doi.org/10.4197/Eco.23-1.5 (in Arabic)

Massoud, S., \& Marzouki, M. (2010). International accounting standardization: the potential and the current. International Forum under the title: The new financial accounting system under the international accounting standards, University Center, Wadi-Janafi. (in Arabic)

Metwally, T. (2007). A proposed model for measuring the size and quality of voluntary disclosure applied to the business environment in the Kingdom of Saudi Arabia. Journal of Trade and Finance, 1, 1-36. (in Arabic)

Mitton, T. (2002). A cross-firm analysis of the impact of corporate governance on the East Asian financial crisis. Journal of Financial Economics, 64(2), 215-241. https://doi.org/10.1016/S0304-405X(02)00076-4

Oluwagbemiga, E. O. (2014). The use of voluntary disclosure in determining the quality of financial statements: Evidence from the Nigeria listed companies. Serbian Journal of Management, 9(2), 263-280. https://doi.org/10.5937/sjm9-5784

Robb, S. W., \& Zarzeski, L. E. S. T. (2001). Nonfinancial disclosures across AngloAmerican countries. Journal of International Accounting, Auditing and Taxation, 10(1), 71-83. https://doi.org/10.1016/S1061-9518(01)00036-2

Yuen, C. Y., Liu, M., Zhang, X., \& Lyu, C. (2009). A case study of voluntary disclosure by Chinese enterprises. Asian Journal of Finance \& Accounting, 1(2), 118-145. https://doi.org/10.5296/ajfa.v1i2.121

Zyod, N, Al-Othman, M., \& Ali, R. (2011). The level of voluntary disclosure in published financial reports of public shareholding companies registered on the Damascus Stock Exchange. Tishreen University Journal for Research and Scientific Studies - Series of Economic and Legal Sciences, 33(3), 27-44. (in Arabic)

ملحق رقم (1) - (1)

\begin{tabular}{|c|c|c|c|}
\hline \multicolumn{4}{|c|}{ قائمة فحص الإفصاح الاختياري } \\
\hline النسبة & الثركات & المعلومات العامة عن الثركة الثمة & \\
\hline $67 \%$ & 30 & الإفصاح عن معلومات عامة عن الاقتصاد & 1 \\
\hline $89 \%$ & 40 & 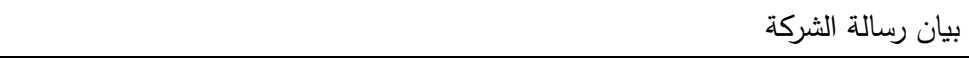 & 2 \\
\hline $80 \%$ & 36 & وصف للهيكل التنظيمي للشركة & 3 \\
\hline $93 \%$ & 42 & معلومات تاريخية مختصرة عن الشركة (النشأة والتطور) & 4 \\
\hline $80 \%$ & 36 & تأثير العوامل البيئية المحيطة ( الظروف السياسية والاقتصادية) في نتائج أعمال الشركة & 5 \\
\hline
\end{tabular}




\begin{tabular}{|c|c|c|c|}
\hline \multicolumn{4}{|c|}{ قائمة فحص الإفصاح الاختياري } \\
\hline 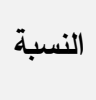 & الثركات & 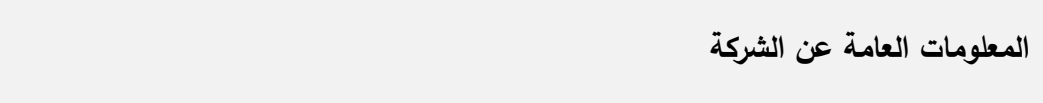 & \\
\hline $87 \%$ & 39 & وصف للسلع أو المنتجات الرئيسية في الشركة & 6 \\
\hline $56 \%$ & 25 & تحليل للحصة السوقية للشركة ل & 7 \\
\hline $76 \%$ & 34 & بيان بالعملاء والموردين الرئيسين للشركة & 8 \\
\hline $69 \%$ & 31 & بيان للوضع التتافسي في الصناعة (تحليل المنافسين) & 9 \\
\hline $51 \%$ & 23 & وصف بالثبكة التسويقية الخاصة بسلع ومنتجات أو خدمات الشركة & 10 \\
\hline $56 \%$ & 25 & الطاقة الإنتاجية للشركة & 11 \\
\hline $64 \%$ & 29 & وصف وتحليل للمشروعات الاستثارية & 12 \\
\hline $67 \%$ & 30 & تحليلات للشركات المتحدة أو للفروع (نظرة عامة، نظرة تاريخية مختصرة، العمليات، الكساهمة) & 13 \\
\hline $42 \%$ & 19 & وصف اللبرامج التأمينية للشركة & 14 \\
\hline $36 \%$ & 16 & طرق وبرامج مراقبة الجودة & 15 \\
\hline $31 \%$ & 14 & الجوائز التي حصلت عليها الثركة & 16 \\
\hline $84 \%$ & 38 & مساهمة الثركة في الاقتصاد الوطني & 17 \\
\hline $89 \%$ & 40 & قضايا هامة خلال العام & 18 \\
\hline \multicolumn{2}{|c|}{$68 \%$} & الإجمالي & \\
\hline \multicolumn{4}{|c|}{ معلومات عن لجنة التدقيق } \\
\hline $73 \%$ & 33 & بيان بدور ووظيفية لجنة التدقيق & 19 \\
\hline $60 \%$ & 27 & أسماء ومؤهلات أعضاء لجنة التدقيق & 20 \\
\hline $53 \%$ & 24 & عدد أعضاء لجنة التدقيق & 21 \\
\hline $27 \%$ & 12 & عدد الاجتماعات التي عقدت خلال العام للجنة التدقيق & 22 \\
\hline $18 \%$ & 8 & عدد الحاضرين لاجتماعات لجنة التدقيق & 23 \\
\hline $47 \%$ & 21 & الإفصاح عن استقلالية لجنة التدقيق & 24 \\
\hline $71 \%$ & 32 & تقرير عن الأعمال المنجزة من قبل لجنة التدقيق & 25 \\
\hline \multicolumn{2}{|c|}{$50 \%$} & الإجمالي & \\
\hline \multicolumn{4}{|c|}{ الافصاحات الخاصة بهيكلية مجلس الإدارة } \\
\hline $98 \%$ & 44 & أسماء وأعمار وعناوين مجلس الإدارة & 26 \\
\hline $93 \%$ & 42 & المؤهلات العلمية والأكاديمية لمجلس الإدارة & 27 \\
\hline $87 \%$ & 39 & الخبرات والمهارات التي يتمتع بها مجلس الإدارة & 28 \\
\hline $91 \%$ & 41 & مدى اهتمام مجلس الإدارة في منافسة الشركات الأخرى & 29 \\
\hline $96 \%$ & 43 & مقدار مساهمة أعضاء مجلس الإدارة في الثركة (الأسهم وغيرها) & 30 \\
\hline $76 \%$ & 34 & عدد الاجتماعات لكل سنة & 31 \\
\hline $80 \%$ & 36 & أسس تحديد منح المكافات والتعويضات لاعضاء مجلس الادارة & 32 \\
\hline \multicolumn{2}{|c|}{$89 \%$} & الإجمالي & \\
\hline \multicolumn{4}{|c|}{ معلومات عن الحوكمة } \\
\hline $60 \%$ & 27 & مدى وجود لجنة للحوكمة & 33 \\
\hline
\end{tabular}




\begin{tabular}{|c|c|c|c|}
\hline \multicolumn{4}{|c|}{ قائمة فصص الإفصاح الاختياري } \\
\hline 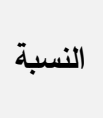 & الثركات & المعلومات العامة عن الشركة & \\
\hline $40 \%$ & 18 & بيان أسماء أعضاء لجنة الحوكمة ومؤهلاتهم & 34 \\
\hline $49 \%$ & 22 & مهام لجنة الحوكمة & 35 \\
\hline $24 \%$ & 11 & عدد الاجتماعات خلال العام & 36 \\
\hline $38 \%$ & 17 & معلومات عن الالتزام بقواعد الحوكمة & 37 \\
\hline \multicolumn{2}{|c|}{$42 \%$} & الإجمالي & \\
\hline & & معلومات عن الإدارة العليا & \\
\hline $91 \%$ & 41 & خبرات الإدارة المديرين & 38 \\
\hline $84 \%$ & 38 & الثهادات العلمية للمديرين & 39 \\
\hline $89 \%$ & 40 & تقسيم المديرين إلى تتفيذين وغير تتفيذيين & 40 \\
\hline $82 \%$ & 37 & تقرير عن مسؤلية المديرين في اعداد التقارير المالية & 41 \\
\hline \multicolumn{2}{|c|}{$87 \%$} & الإجمالي & \\
\hline \multicolumn{4}{|c|}{ |فصاحات عن تحليلات مالية وغير مالية } \\
\hline $82 \%$ & 37 & ملخص عن البيانات المالية لثلاث سنوات سابقة أو أكثر & 42 \\
\hline $73 \%$ & 33 & معلومات عن سعر السهم & 43 \\
\hline $2 \%$ & 1 & ارفاق قوائم مالية معدلة بعد احتساب التضخم وأثره عليها & 44 \\
\hline $2 \%$ & 1 & تأثير التضخم على مستقبل عمليات المنثاة & 45 \\
\hline $56 \%$ & 25 & القروض البنكية والرهن واستخداماتها & 46 \\
\hline $82 \%$ & 37 & مصاريف الدعاية والاعلان & 47 \\
\hline $87 \%$ & 39 & معلومات عن التقلبات في أسعار العملات الأجنبية خلال العام & 48 \\
\hline $47 \%$ & 21 & معلومات ربما تؤثر على الأداء المستقبلي للشركة & 49 \\
\hline $60 \%$ & 27 & الإفصاح عن أي منتجان أو خدمات جديدة & 50 \\
\hline $58 \%$ & 26 & الخطة التسويقية و الخطة التوسعية في نظام التوزيع & 51 \\
\hline $44 \%$ & 20 & خطة التوسع في المبيعات & 52 \\
\hline $47 \%$ & 21 & تأثير استراتيجية الثركة على نتائج أعمالها المستقبلية & 53 \\
\hline $7 \%$ & 3 & بيان بمصروفات البحث والتطوير & 54 \\
\hline $91 \%$ & 41 & بيان بالتدفقات النقدية & 55 \\
\hline $11 \%$ & 5 & بيان بمصروفات الدعاية والاعلان المتوقعة & 56 \\
\hline $20 \%$ & 9 & التوقعات بربحية السهم لكل سهم & 57 \\
\hline $16 \%$ & 7 & تتبؤات بالمبيعات المستقبلية & 58 \\
\hline $9 \%$ & 4 & بيان بالمصروفات الرأسمالية المتوقعة & 59 \\
\hline $13 \%$ & 6 & التنبؤات بالأرباح المستقبلية & 60 \\
\hline \multicolumn{2}{|c|}{$42 \%$} & الإجمالي & \\
\hline \multicolumn{3}{|c|}{ معلومات عن العاملين في الثركة وافصاحات عن المسؤولية الاجتماعية والسياسات البيئية } & \\
\hline $73 \%$ & 33 & إجمالي عدد الموظفين لاخر عامين أو أكثر & 61 \\
\hline
\end{tabular}




\begin{tabular}{|c|c|c|c|}
\hline \multicolumn{4}{|c|}{ قائمة فحص الإفصاح الاختياري } \\
\hline 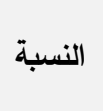 & الثركات & المعلومات العامة عن الشركة & \\
\hline $82 \%$ & 37 & تصنيف الموظفين حسب الجنس & 62 \\
\hline $89 \%$ & 40 & مقدار مكافات الممنوحة للموظفين والسياسة المتبعة ل لمنحها. & 63 \\
\hline $56 \%$ & 25 & فئات ونوعية الموظفين الذين حصلوا على تدريب في الثركة & 64 \\
\hline $47 \%$ & 21 & السياسة المستخدمة في التدريب & 65 \\
\hline $49 \%$ & 22 & المصروفات المخصصة لتدريب الموظفين & 66 \\
\hline $7 \%$ & 3 & مبررات التغيير في عدد الموظفين & 67 \\
\hline $58 \%$ & 26 & المؤهلات العلمية للمحاسبين & 68 \\
\hline $11 \%$ & 5 & افصاحات عن حوادث العمل & 69 \\
\hline $22 \%$ & 10 & سياسة الضمان الاجتماعي & 70 \\
\hline $7 \%$ & 3 & سياسة التدوير الوظيفي & 71 \\
\hline $22 \%$ & 10 & سياسات التوظيف & 72 \\
\hline $29 \%$ & 13 & افصاح عن نظام السلامة والأمان & 73 \\
\hline $27 \%$ & 12 & تكلفة إجراءات السلامة والأمان & 74 \\
\hline $47 \%$ & 21 & مساهمات الثركة الاجتماعية & 75 \\
\hline $38 \%$ & 17 & برامج حماية البيئة & 76 \\
\hline $67 \%$ & 30 & الإعانات والتبرعات المقدمة للاخرين & 77 \\
\hline $69 \%$ & 31 & الهبات والمنح & 78 \\
\hline \multicolumn{2}{|c|}{$44 \%$} & الإجمالي & \\
\hline \multicolumn{4}{|c|}{ تكاليف البحث والتطوير } \\
\hline $73 \%$ & 33 & سياسة البحث والتطوير & 79 \\
\hline $7 \%$ & 3 & عدد العاملين في البحث والتطوير & 80 \\
\hline $2 \%$ & 1 & المخصصات المالية للبحث والتطوير & 81 \\
\hline $2 \%$ & 1 & التكلفة الفعلية لنشاطات البحث والتطوير خلال السنتين السابقتين & 82 \\
\hline $9 \%$ & 4 & مشروعات البحث والتطوير القائمة & 83 \\
\hline $20 \%$ & 9 & النتائج المحققة من البحوث والتطوير & 84 \\
\hline \multicolumn{2}{|c|}{$19 \%$} & الإجمالي & \\
\hline
\end{tabular}

